\title{
Pulsed-Laser Switching in the Bistability Domain of a Cooperative Spin Crossover Compound: A Critical Study through Calorimetry
}

Miguel Castro, Olivier Roubeau, Lucía Piñeiro-López, Jose A. Real, and Jose Alberto Rodriguez-Velamazan

J. Phys. Chem. C, Just Accepted Manuscript • DOI: 10.1021/acs.jpcc.5b05864 • Publication Date (Web): 30 Jun 2015

Downloaded from http://pubs.acs.org on July 2, 2015

\section{Just Accepted}

"Just Accepted" manuscripts have been peer-reviewed and accepted for publication. They are posted online prior to technical editing, formatting for publication and author proofing. The American Chemical Society provides "Just Accepted" as a free service to the research community to expedite the dissemination of scientific material as soon as possible after acceptance. "Just Accepted" manuscripts appear in full in PDF format accompanied by an HTML abstract. "Just Accepted" manuscripts have been fully peer reviewed, but should not be considered the official version of record. They are accessible to all readers and citable by the Digital Object Identifier (DOI®). "Just Accepted" is an optional service offered to authors. Therefore, the "Just Accepted" Web site may not include all articles that will be published in the journal. After a manuscript is technically edited and formatted, it will be removed from the "Just Accepted" Web site and published as an ASAP article. Note that technical editing may introduce minor changes to the manuscript text and/or graphics which could affect content, and all legal disclaimers and ethical guidelines that apply to the journal pertain. ACS cannot be held responsible for errors or consequences arising from the use of information contained in these "Just Accepted" manuscripts. 


\title{
Pulsed-Laser Switching in the Bistability Domain of a Cooperative Spin Crossover Compound: A Critical
}

\section{Study through Calorimetry}

\author{
M. Castro ${ }^{+}$, O. Roubeau ${ }^{+}$, L. Piñeiro-López ${ }^{\#}, J$. A. Real ${ }^{\#}, J$. A. Rodríguez-Velamazán ${ }^{+, \$}$ \\ ${ }^{+}$Instituto de Ciencia de Materiales de Aragón (ICMA), CSIC and Universidad de Zaragoza, \\ Spain; "Instituto de Ciencia Molecular (ICMol), Universidad de Valencia, 46980 Paterna, \\ Valencia, Spain; ${ }^{\$}$ Institut Laue-Langevin, 38042 Grenoble Cedex 9, France \\ AUTHOR INFORMATION \\ Corresponding Author
}

Tel: 00-34-976762528

Fax: 00-34-976761957

*E-mail: mcastro@unizar.es 


\begin{abstract}
The photo-switching from low spin (LS) to high spin (HS) state and the reverse process in the bistability domain of spin crossover compounds ( $\mathrm{SCO}$ ) is a promising function to be used in molecular electronic devices, evidenced mainly through spectroscopy. The phenomenon, and in particular its mechanism, is however still under debate since some controversial experimental results have been reported. Here we present a calorimetric experimental study of the photoswitching of the $\left[\mathrm{Fe}(\right.$ pyrazine $\left.) \mathrm{Pt}(\mathrm{CN})_{4}\right] \mathrm{SCO}$ material by a nanosecond-pulsed green laser. Our results confirm single laser pulse of varying energies result in significant LS to HS transformations and show that calorimetry provides an accurate quantification of the overall conversion. Successive pulses allow increasing the conversion, achieving a maximum of $60 \%$ under our experimental conditions. The HS to LS transformation is on the other hand not induced at any laser fluences contrary to previous reports. The results are compared with those reported with Raman spectroscopy and critically discussed in terms of efficiency of the transformation and potential thermal effects.
\end{abstract}

KEYWORDS Spin Transition; thermal analysis; photo-induced transitions; iron compounds; porous coordination polymers. 


\section{INTRODUCTION}

The control of the magnetic properties of molecular compounds by external stimuli, including temperature, light, pressure, electric or magnetic field is an important scientific topic spurred on by envisaged uses in molecular spintronics as memory storage, transistors and switching devices.

${ }^{1}$ Among these switchable magnetic materials, $\mathrm{Fe}^{\mathrm{II}}$ spin crossover (SCO) compounds ${ }^{2,3}$ are one of the most interesting systems, due the spin transition between a diamagnetic low spin state (LS, $S$ $=0)$ and a paramagnetic high spin state (HS, $S=2$ ), associated with changes in various physical properties (optical, electrical and structural), induced by an external perturbation. The wellstudied switching induced by light, so-called Light-Induced Excited Spin State Trapping (LIESST), ${ }^{4}$ is however limited to low temperatures by the thermally-activated relaxation of the metastable trapped HS state. Recently, a novel approach has been considered to obtain photoinduced reversible spin state switching at higher temperature; it contemplates irradiation within the bistability domain of SCO materials with a large thermal hysteresis loop, characteristic of the presence of a first-order transition. In such conditions, the light-trapped species are expected to be stable, as long as the system is maintained within the bistability conditions. A few promising reports demonstrating the validity of the approach have already been published. The first experimental result was obtained measuring the optical reflectivity of the $\left[\mathrm{Fe}(\mathrm{PM}-\mathrm{BiA})_{2}(\mathrm{NCS})_{2}\right]$ compound (PM-BiA = N-2'-pyridylmethylene-4-aminobiphenyl), for which a large stationary photo-induced HS fraction $(\alpha=0.6)$ was produced within the thermal hysteresis loop from the initial LS state by a single green laser nanosecond-pulse. ${ }^{5}$ Neither larger HS fractions, through additional pulses, nor the reverse switching, attempted with various wavelengths and fluences, could however be obtained. In the SCO complex $\left[\mathrm{FeL}(\mathrm{CN})_{2}\right] \cdot \mathrm{H}_{2} \mathrm{O}\left(\mathrm{L}=\mathrm{N}_{3} \mathrm{O}_{2}\right.$ Schiff-base macrocyclic ligand) the photo-excitation from a HS:LS $(1: 1, \alpha=0.5)$ mixture state to $\alpha \approx 0.88$ of 
HS species was produced using a single-shot laser pulse and monitored through absorption spectra. ${ }^{6}$ This work evidenced the existence of threshold values both in wavelength and in laser fluence to trigger the photo-excitation. The mechanism in this specific system however likely involves a change in coordination number and is thus not a simple SCO process. Several papers ${ }^{7-}$ ${ }^{9}$ on the $\left[\mathrm{Fe}(\mathrm{pz}) \mathrm{Pt}(\mathrm{CN})_{4}\right] \mathrm{SCO}$ compound $(\mathrm{pz}=$ pyrazine) used Raman spectroscopy to monitor the effect of the light excitation. In this case and for a polycrystalline powder sample, bidirectional photo-induced process (LS to HS and HS to LS) was obtained using the same nanosecond-pulsed green laser. ${ }^{7}$ Photo-switching from the LS state was probed at several temperatures within the hysteresis loop reaching a HS fraction of $\alpha=0.2$ for a single laser pulse and 0.4 after a second pulse was applied. Surprisingly, no further increase in HS fraction was detected with additional pulses, while a quite large laser fluence of $250 \mathrm{~mJ} / \mathrm{cm}^{2}$ was used. In a later study ${ }^{9}$ a $100 \%$ conversion could be reached using a much lower laser fluence of at least 20 $\mathrm{mJ} / \mathrm{cm}^{2}$, with a threshold value of around $5 \mathrm{~mJ} / \mathrm{cm}^{2}$. On a polycrystalline powder sample, the reverse transformation could only be produced from a HS-LS mixture state (with an initial LS fraction of 0.3$).^{7}$ On the other hand, a complete bidirectional photo-excitation was obtained on single-crystals, again using the same nanosecond-pulsed green laser. ${ }^{8}$ In this case, the HS to LS phase transformation was achieved from a full HS state and using a low laser fluence $(\approx 5$ $\mathrm{mJ} / \mathrm{cm}^{2}$ ) that had no effect in the case of the polycrystalline sample. The photo-excitation within the hysteresis loop can also be performed using a continuous laser irradiation as shown by Raman spectroscopy with a complete LS to HS conversion of the $\left[\mathrm{Fe}\left(\mathrm{H}_{4} \mathrm{~L}\right)_{2}\right]\left(\mathrm{ClO}_{4}\right)_{2} \cdot \mathrm{H}_{2} \mathrm{O} \cdot 2\left(\mathrm{CH}_{3}\right)_{2} \mathrm{CO} \quad \mathrm{SCO} \quad$ compound $\quad\left(\mathrm{H}_{4} \mathrm{~L} \quad=\quad\right.$ 2,6-bis $(5-(2-$ hydroxyphenyl)pyrazol-3-yl)pyridine). ${ }^{10}$ Single-pulse photo-switching was also attempted in triazole-based $1 \mathrm{D}$ polymeric spin crossover compounds. ${ }^{11} \operatorname{In}\left[\mathrm{Fe}^{\mathrm{II}}(\mathrm{Htrz})_{2}(\operatorname{trz})\right]\left(\mathrm{BF}_{4}\right)(\mathrm{Htrz}=1-\mathrm{H}-$ 
1,2,4-triazole) a bidirectional switching, i.e. LS to HS and HS to LS, was detected through Raman spectroscopy by pulsed green irradiation at the same wavelength but only when the excitation was done at temperatures close to the ascending (378 K) and descending (351 K) branches of its large thermal hysteresis loop. ${ }^{12}$ No effect could however be detected when the excitation was performed at temperatures in the centre of the hysteresis loop.

In all these experimental reports the sample heating due to the irradiation was considered to have no significant effect on the detected phenomenology, although some unexplained aspects such as the reversibility of the process using an identical wavelength for which drastically different absorption densities are detected in the HS and LS states or the necessity to be close to (or even within) the thermal phase transition for realizing the switching may originate in thermally-related effects. These would mostly result from a local (surface) over-heating, over a very short time-scale and thus difficult to detect, and include a thermally-induced LS to HS transformation due to sufficient heating or a thermally-induced HS to LS transformation resulting from the response of temperature control to local heating. The former has indeed more recently been proposed as the origin of the impossibility to perform the HS to LS phase transformation in $\left[\mathrm{Fe}(\mathrm{PM}-\mathrm{BiA})_{2}(\mathrm{NCS})_{2}\right]$, whatever the wavelength and fluence used, ${ }^{13}$ as well as the main source of laser-induced switching in the SCO compounds $\left[\mathrm{Fe}\left(\mathrm{NH}_{2}-\mathrm{trz}\right)_{3}\right]\left(\mathrm{NO}_{3}\right)_{2} \cdot \mathrm{H}_{2} \mathrm{O}$ and $\left[\mathrm{Fe}\left(\mathrm{NH}_{2}-\mathrm{trz}\right)_{3}\right](\mathrm{Br})_{2} \cdot 3 \mathrm{H}_{2} \mathrm{O} .{ }^{14-16}$ In these latter studies, the authors used time-resolved optical reflectivity data, thus accessing only the surface response, and considered huge local heating. Additionally, a large local temperature gradient will produce a heat transfer to the rest of the material increasing its temperature until a common temperature is reached when thermal equilibrium is obtained with the surrounding. This has in fact been directly observed with Raman microscopy with micro-scale spatial resolution, showing a LS to HS conversion outside the 
irradiated region in $\left[\mathrm{Fe}^{\mathrm{II}}(\mathrm{Htrz})_{2}(\mathrm{trz})\right]\left(\mathrm{BF}_{4}\right) .{ }^{17}$ Although performed on a non cooperative $\mathrm{Fe}^{\mathrm{III}} \mathrm{SCO}$ compound, time resolved single-crystal optical and X-Ray diffraction studies actually revealed for the first time a multistep process including photo, elastic and thermal-induced phenomena occurring at different timescales. ${ }^{18,19}$ Recently, the same research group has also detected these consecutive three steps on a cooperative $\mathrm{Fe}^{\mathrm{III}} \mathrm{SCO}$ compound $^{20,21}$ (excitation was performed on the LS state but outside of the thermal hysteresis loop) and they conclude that a strong response in this case is mainly due to the temperature increase caused by the laser excitation which allows the sample to surpass its spin transition temperature where the abrupt conversion to HS state happens. Eventually, the dynamics of the growing or contraction of laser induced initial HS domains and the related accommodation strain is very likely to play a role. ${ }^{22}$

Altogether, and although there is no doubt single-laser pulse in the bistability domain of cooperative SCO materials does induce LS to HS phase transformations, the true mechanisms for both LS to HS and HS to LS transformations clearly remain disputable. In this respect, it should be noted that all reports so far have been based solely on (local) spectroscopic methods. Bulk structural, magnetic and thermal studies remain clearly necessary to understand, improve and apply the observed phenomena. In this work, we report the first calorimetric study of the laserinduced switching within the bistability domain of a SCO compound. We focus on the spin crossover $\left[\mathrm{Fe}(\mathrm{pz}) \operatorname{Pt}(\mathrm{CN})_{4}\right]$ compound with its spin crossover around room temperature, and test both the LS to HS and HS to LS phase transformations, seeking confirmation of the pulsed-laser switching phenomena and additional insights towards their understanding. 


\section{EXPERIMENTAL METHODS}

\section{Synthesis and sample description}

A microcrystalline powder (PP) and mono-crystalline (SC) (ca. 40-80 microns) samples of the dehydrated form of the spin crossover compound $\left[\mathrm{Fe}(\right.$ pyrazine $\left.)\left(\mathrm{Pt}(\mathrm{CN})_{4}\right)\right]$ were obtained as previously described. ${ }^{23}$ Both samples show orange color at room temperature indicative of a HS state. An aged PP sample (APP) taken from the same batch but after one year stored in a plastic bag at room temperature has been also used in some calorimetric experiments.

\section{Experimental calorimetric set up}

A differential scanning calorimeter (DSC) model Q1000 from TA instruments equipped with a liquid nitrogen cooling system (LNCS) in order to reach low temperature has been used. The irradiation of the sample was performed keeping open the oven and using the photo-calorimetric commercial accessories (PCA) that allow illuminating the sample inside the oven while it is under the helium gas atmosphere. In order to remove traces of water molecules possibly absorbed from air moist, the sample was submitted to an initial thermal treatment at $140^{\circ} \mathrm{C}$ during 30 min inside the DSC oven and under Helium gas atmosphere before proceeding with the calorimetric measurements. Irradiation was done when the calorimeter was operating in the isothermal mode, that is, the instrument was set to maintain constant the selected temperature ( $T_{\text {irradiation }}$ ). Thermograms (cooling and heating) were performed at a scan rate of $10 \mathrm{~K} / \mathrm{min}$. The sample masses were 1.10, 0.87 and $0.97 \mathrm{mg}$ for PP, APP and SC samples respectively. The sample was spread on the aluminium pan (6 $\mathrm{mm}$ of diameter) and covered by a thin fused silica plate in order to avoid the loss of material. A pulsed $\mathrm{Nd}^{3+}$ : YAG laser (LOTIS TII LS-2134U) operating at $532 \mathrm{~nm}$ with a pulse width of 7-8 ns was used as the excitation source. The spot size is $6 \mathrm{~mm}$ allowing the irradiation of the complete aluminium pan and therefore the whole sample. 
All this photo-calorimetric system is shown in Figure 1. In order to estimate the laser fluence $\left(\mathrm{mJ} / \mathrm{cm}^{2}\right)$, graphite powder (mass around $0.1 \mathrm{mg}$ ) was used as a good absorbing sample so the whole pulse energy is converted into heat. It was also spread on the pan as a thin film and covered by the fused silica plate, and the DSC heat flow peak, required for keeping constant the temperature after the laser pulse, was determined. Results are shown in Figure S1 included in the Supporting information.

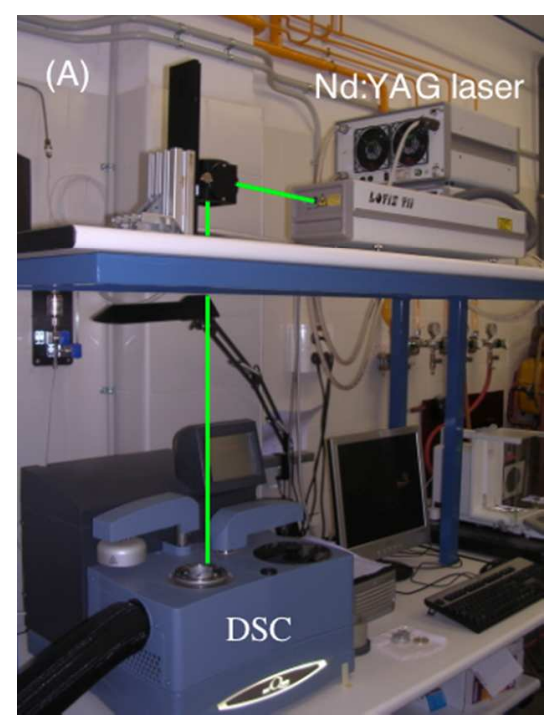

Figure 1. Experimental photo-calorimetric set up.

\section{Additional magnetic, spectroscopic and structural characterization}

Magnetic measurements on SC sample were performed with an MPMS-XL SQUID magnetometer from Quantum design in the 200 - $340 \mathrm{~K}$ temperature range and under 1 Tesla applied field. The SC sample was warmed to $140^{\circ} \mathrm{C}$ for $30 \mathrm{~min}$ in a desiccator, before performing magnetic measurements.

Single-crystal X-Ray diffraction was performed at 310 and $240 \mathrm{~K}$ on the SC sample using an Oxford Diffraction Xcalibur diffractometer with enhanced Mo Ka radiation $(\lambda=0.71071 \AA)$ at the X-ray and Fluorescence Analysis Service of the Servicio General de Apoyo a la 
Investigación-SAI, Universidad de Zaragoza. Cell refinement, data reduction and absorption corrections were performed with the CrysAlisPro suite. ${ }^{24}$ The structure was solved with SIR97 ${ }^{25}$ and refined on $F^{2}$ with the SHELXTL suite. ${ }^{26,27}$

The visible absorption spectra of a powder sample near room temperature has been obtained for both LS and HS state by diffuse reflectance and using a Jasco V-60 UV/Vis/NIR spectrophotometer equipped with PIV-756/PIN 757 horizontal sampling integrating sphere system.

The corresponding results provided in the supporting information, are in agreement with previously reported data, and support the spin transition as detected through DSC.

\section{RESULTS AND DISCUSSION}

The three-dimensional porous coordination network $\left[\mathrm{Fe}(\mathrm{pz}) \mathrm{Pt}(\mathrm{CN})_{4}\right]$ was first reported in 2001 in its hydrated form ${ }^{23}$, that exhibits a hysteretic SCO with $T_{1 / 2 \text {, cooling }}=220 \mathrm{~K}$ and $T_{1 / 2 \text {, heating }}=240$ K. ( $T_{1 / 2}$ being the temperature at which HS and LS states have equal populations). Removal of the lattice solvent water molecules by heating to $120-130{ }^{\circ} \mathrm{C}$ for $30 \mathrm{~min}$ results in dehydrated $\left[\mathrm{Fe}(\mathrm{pz}) \mathrm{Pt}(\mathrm{CN})_{4}\right](\mathbf{1})$, which is stable when kept in a dry atmosphere, and only slowly reabsorbs water from air moist. Dehydration can be done on single crystals without loss of crystallinity, and results in a shift of the hysteresis towards higher temperature. Polycrystalline powders and single-crystals of $\mathbf{1}$ or partially re-hydrated $\mathbf{1}$ have very similar SCO properties with a large and rather abrupt hysteresis centred on room temperature; only slight variations of the transition temperatures have been reported, values of $T_{1 / 2}$ cooling ranging $283-291 \mathrm{~K}$ and $T_{1 / 2}$ heating ranging 305-311 K, with an hysteresis width of 24 to $28 \mathrm{~K}^{7,8,23,28}$ This compound has been extensively 
studied and a collection of interesting properties has been reported like the chemoswitching ${ }^{29}$ between HS and LS states and molecular rotation correlated with the change of the spin state. ${ }^{30}$

The thermograms, i.e. heat flow vs. temperature scans, obtained at $10 \mathrm{~K} / \mathrm{min}$ are represented in Figure 2 for the studied PP (Figure 2A), APP (Figure 2B) and SC (Figure 2C) samples of $\left[\mathrm{Fe}(\right.$ pyrazine $\left.)\left(\mathrm{Pt}(\mathrm{CN})_{4}\right)\right]$ respectively. These measurements are fully reproducible and depict the first order spin transition exhibited by this compound. Temperatures corresponding to the maximum of the peaks together with their enthalpy and entropy contents are gathered in Table 1.
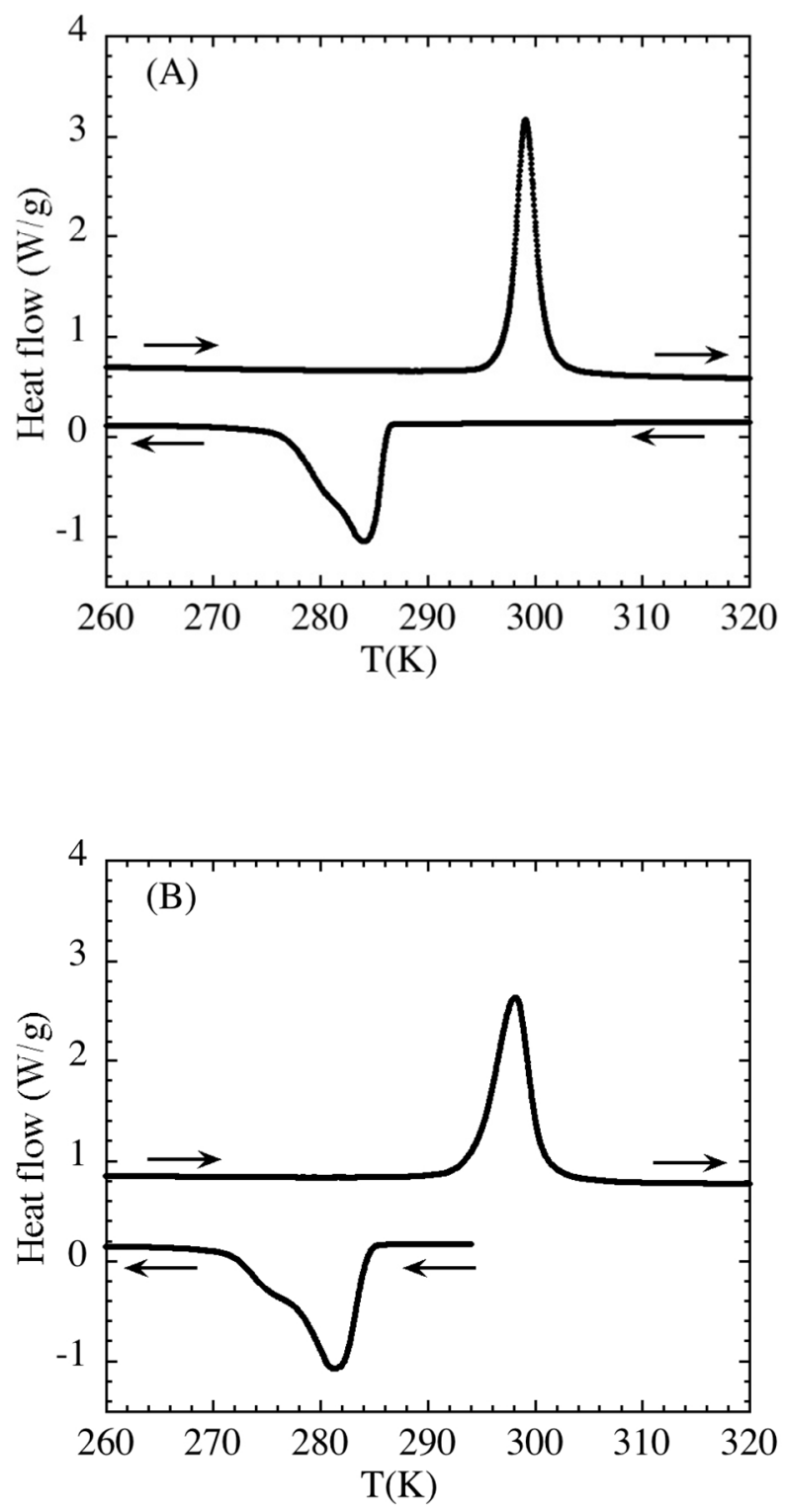


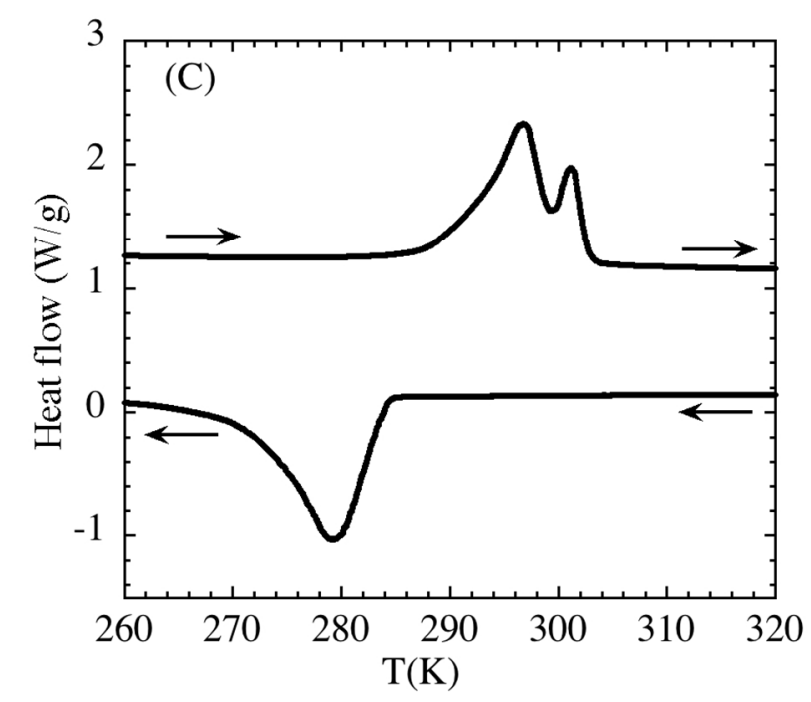

Figure 2. Heating and cooling thermograms for: (A) Microcrystalline powder (PP) sample, (B) aged microcrystalline powder (APP) sample and (C) Mono-crystalline (SC) sample.

Table 1. Characteristic temperatures and thermodynamic contents for the three studied samples of $\mathbf{1}$, as determined from calorimetric measurements.

\begin{tabular}{|c|c|c|c|c|c|c|c|c|}
\hline Sample & $\begin{array}{c}T_{\text {heating }} \\
(\mathrm{K})\end{array}$ & $\begin{array}{c}\Delta H_{\text {heating }} \\
(\mathrm{kJ} / \mathrm{mol})\end{array}$ & $\begin{array}{c}\Delta S_{\text {heating }} \\
(\mathrm{J} / \mathrm{mol} \mathrm{K})\end{array}$ & $\begin{array}{c}T_{\text {cooling }} \\
(\mathrm{K})\end{array}$ & $\begin{array}{c}\Delta H_{\text {cooling }} \\
(\mathrm{kJ} / \mathrm{mol})\end{array}$ & $\begin{array}{c}\Delta S_{\text {cooling }} \\
(\mathrm{J} / \mathrm{mol} \mathrm{K})\end{array}$ & $\begin{array}{c}T_{1 / 2, \text { heating }} \\
(\mathrm{K})\end{array}$ & $\begin{array}{c}T_{1 / 2, \text { cooling }} \\
(\mathrm{K})\end{array}$ \\
\hline PP & 299.1 & 19.3 & 66 & 283.9 & 20.5 & 75 & 299.2 & 282.4 \\
\hline APP & 298.1 & 21.3 & 72 & 281.3 & 22.8 & 82 & 297.6 & 279.8 \\
\hline SC & $296.2 / 301.2$ & 21 & 72 & 279.2 & 23 & 84 & 296 & 277.8 \\
\hline
\end{tabular}

The three samples show strong but rather broad anomalies on cooling, corresponding to the HS to LS transition, while on heating, for the LS to HS transition, a sharper peak is detected for the PP sample and the SC sample presents two sharp overlapped peaks. The peaks for the APP sample are broader and shifted to slightly lower temperatures. The hysteresis width of SC sample is around $20 \mathrm{~K}$, similar to that for the polycrystalline samples $(15-17 \mathrm{~K})$. Critical temperatures are in the low temperature range of the previously reported temperatures on $\mathbf{1}$. Magnetic 
measurements (see supporting information, Figures S2 and S3) performed on the SC sample are in agreement with the calorimetric data. Additionally, single-crystal X-Ray diffraction on the SC sample confirmed the previously reported structure, with no significant trace of re-absorbed lattice water molecules (see supporting information, Table S1 and Figure S5), and Fe-N bond lengths characteristic of HS and LS state respectively at 310 and $240 \mathrm{~K}$. For the three samples, the presence of significant amounts of re-absorbed water can be discarded since the spin transition occurs at higher temperature than the fully hydrated sample. ${ }^{7,16}$
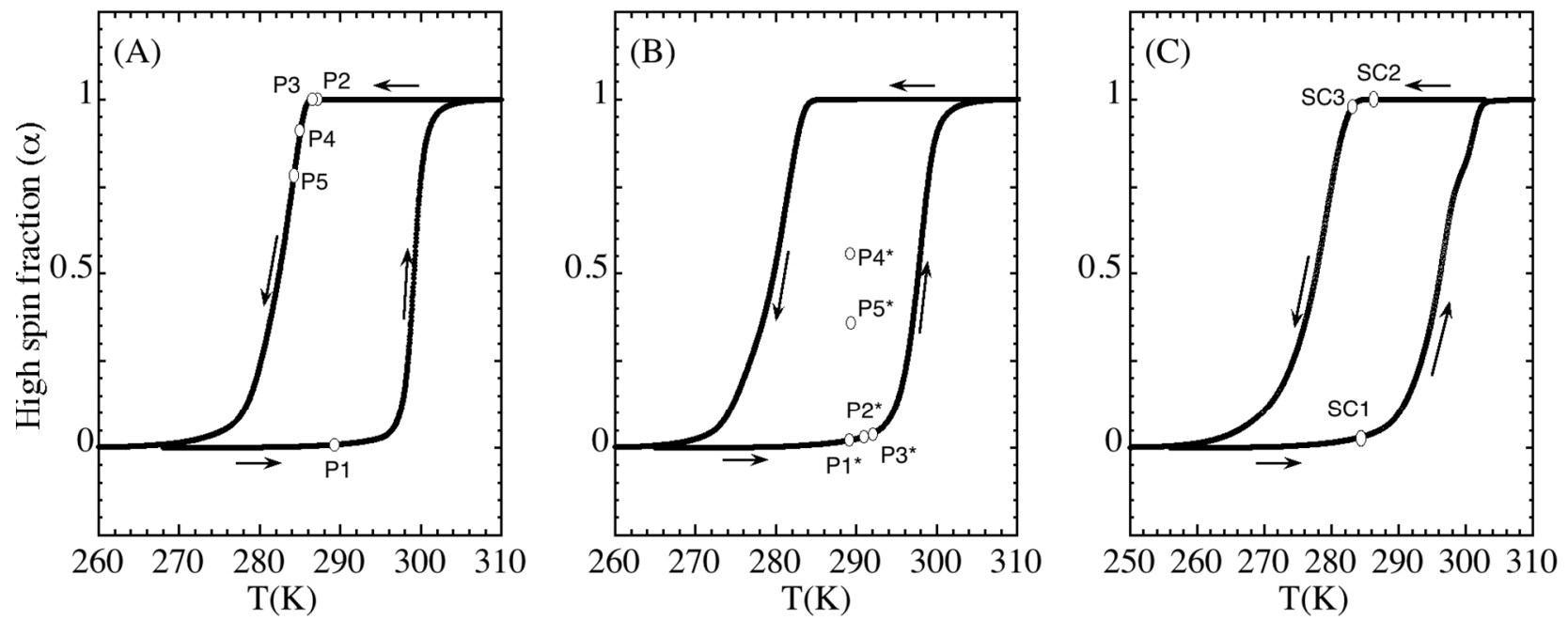

Figure 3. Thermal hysteresis loops for: (A) PP sample, (B) Aged PP sample (APP) and (C) SC sample. Irradiation temperatures $\left(T_{\text {irradiation }}\right)$ for each sample are marked in the respective hysteresis loop and correspond to: $289.15 \mathrm{~K}(\mathrm{P} 1, \mathrm{P} 1 *), 291.15 \mathrm{~K}(\mathrm{P} 2 *), 293.15 \mathrm{~K}(\mathrm{P} 3 *)$ and 284.15 K (SC1) for the case of LS to HS excitation while excitation at $287.15 \mathrm{~K}(\mathrm{P} 2), 286.65 \mathrm{~K}$ (P3), 285.15 K (P4), 284.15 K (P5), 286.15 K (SC2) and 283.15 K (SC3) was done for the HS to LS one. For APP sample, excitation was also performed at $289.15 \mathrm{~K}$ (P4* from heating branch, P5* from cooling branch) when starting from a mixed HS/LS state. 
Figures $3 \mathrm{~A}, 3 \mathrm{~B}$ and $3 \mathrm{C}$ show the thermal hysteresis loops determined from our calorimetric measurements after subtracting the appropriate baselines for the PP, APP and SC samples respectively. The HS fraction, $\alpha(T)$, has been obtained as the ratio between the enthalpy content of the anomaly, $\Delta H(\mathrm{~T})$, calculated by integration of the excess heat flow as temperature increases and the enthalpy content of the complete transformation, that is $\Delta H_{\text {heating }}$ for the LS $\rightarrow$ HS case and $\Delta H_{\text {cooling }}$ for the HS $\rightarrow$ LS one. Critical temperatures, $T_{1 / 2}$, heating and $T_{1 / 2}$, cooling determined from these hysteresis loops for the three samples are collected in Table 1.

Irradiation experiments were performed using $532 \mathrm{~nm}$ laser pulses of varying fluences at

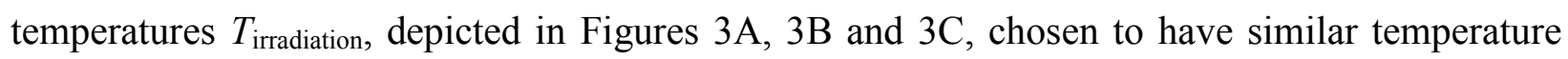
differences with respect to the characteristic temperatures $\left(\Delta T=T_{1 / 2}{ }^{\text {heating }}-T_{\text {irradiation }}\right.$ or $T_{\text {irradiation }}{ }^{-}$ $T_{1 / 2}{ }^{\text {cooling }}$ ) as in the relevant reported works ${ }^{7-9}$ in order to allow comparison.

Let us first describe, following the example for the PP sample shown in Figure 4A, the experimental procedure for the photo-excitation of the LS species in order to induce the HS state. After cooling down from room temperature to a low enough temperature $(253 \mathrm{~K}$ for PP and APP samples and $243 \mathrm{~K}$ for the SC sample) to reach a complete transformation to the LS state (a), the sample is heated up to $T_{\text {irradiation }}$ inside the hysteresis loop (b) (for example P1, P1* and SC1 point in Figure 3A, 3B and 3C respectively, then the sample is still fully LS) and this temperature is maintained constant (c). During this isotherm, a single laser pulse (or several of them) is applied to the sample. Figure 4A shows the case of a single laser pulse applied at 8 min with a laser fluence of $27 \mathrm{~mJ} / \mathrm{cm}^{2}$. A peak on the heat flow is clearly detected corresponding to the response of the calorimeter in order to keep a constant temperature against the effect of the laser pulse that disturbs this isothermal step (see rectangular box in Figure 4A). Finally, the thermogram is recorded on cooling (d) and an anomaly, centred at around $T_{\text {cooling, }}$, is detected corresponding to 
the conversion of HS species to LS state (see circle in Figure 4A and thick line in Figure 4B) thus providing direct evidence that HS species have been produced by the laser pulse.
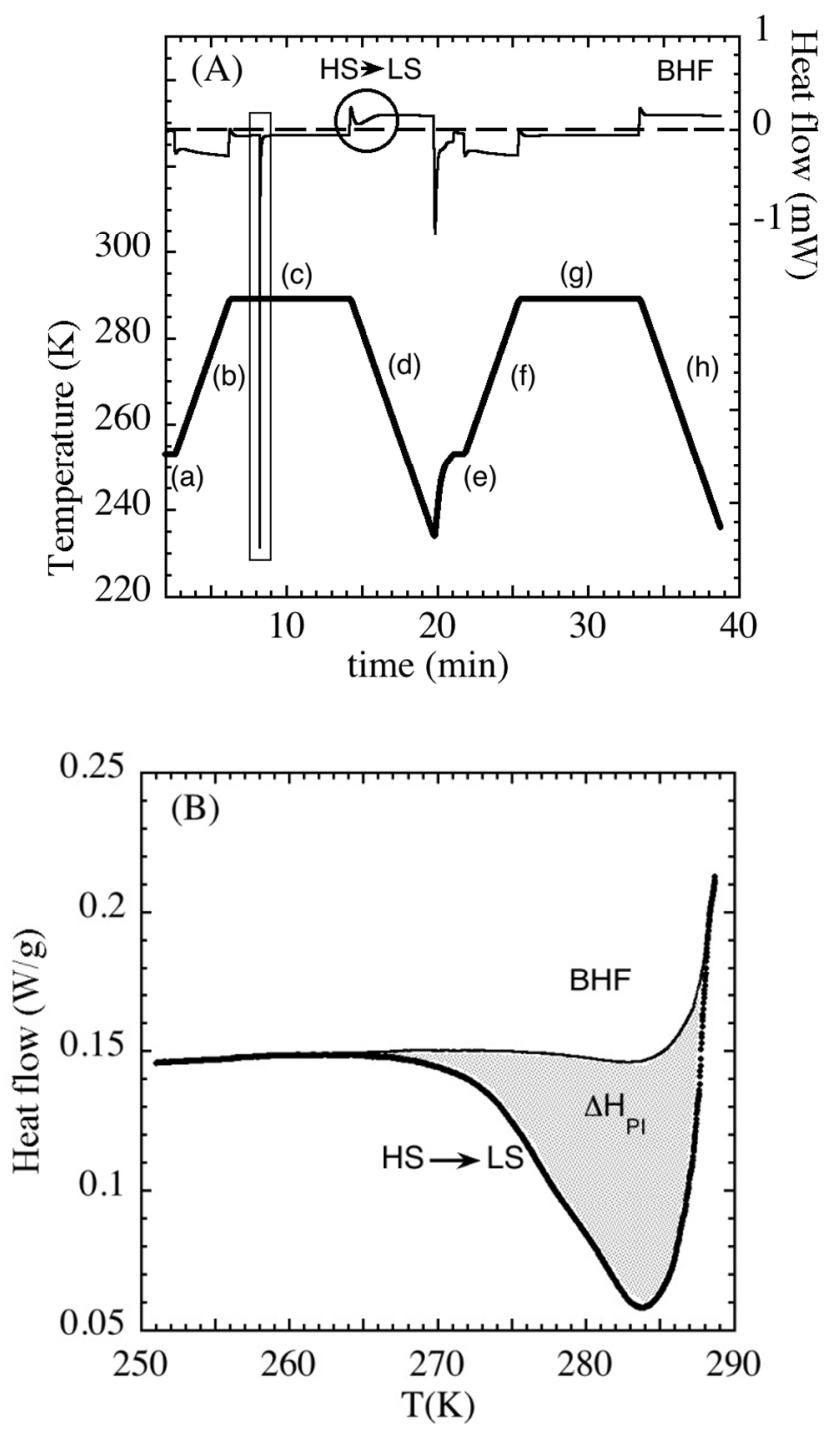

Figure 4. (A) Example of the programmed temperature profile (thick line) and heat flow (thin line) during the experimental procedure, as explained in the text, in order to perform photoexcitation of the LS state. The dashed line represents heat flow equal to zero. Rectangular box: Peak on the heat flow corresponding to the response of the calorimeter in order to keep the sample temperature constant when the laser pulse is applied. Circle: Calorimetric anomaly corresponding to the conversion of the photo-induced HS species to LS state. (B) Process 
followed (see text) to deduce the enthalpy content of the anomaly, $\Delta H_{\mathrm{PI}}$, needed to estimate the HS fraction induced by the irradiation. The thick line is the calorimetric anomaly corresponding to the conversion of the photo-induced HS species to LS state and the thin line is the background heat flow (BHF).

To determine the HS fraction produced by the irradiation, $\alpha$, defined here as the ratio between the enthalpy content of the anomaly, $\Delta H_{\mathrm{PI}}$, and the enthalpy content of the complete HS $\rightarrow$ LS transformation $\Delta H_{\text {cooling }}$ (Table 1), a baseline must be subtracted. This background heat flow, BHF, indicated in Figure 4A and shown in Figure 4B (as a thin line) together with the anomaly for the case of a laser fluence of $27 \mathrm{~mJ} / \mathrm{cm}^{2}$, is obtained subjecting the sample to the exact same thermal history (see Figure 4A: e-f-g-h) but without the application of the laser pulse. The excess heat flow ( $\Delta$ Heat flow) after subtracting the corresponding baseline and for the different irradiation experiments performed at $289.15 \mathrm{~K}(100 \% \mathrm{LS}$ state corresponding to point $\mathrm{P} 1$ in Figure $3 \mathrm{~A}$ ) is shown in Figure 5A for the PP sample together with their enthalpy contents. Similarly, excess heat flow for the case of the APP (for P1* in Figure 3B) and SC (for SC1 in Figure 3C) samples are shown in Figure S6 and S7 respectively.

The results for the three samples are summarized in Figure 5B where $\alpha$ versus the laser fluence is represented and $\Delta T=10 \mathrm{~K}, 8.5 \mathrm{~K}$ and $12 \mathrm{~K}$ for the PP, APP and SC samples respectively. The available data from previous studies on $\mathbf{1}$ using Raman spectroscopy are gathered on the same scale to allow proper comparison. 

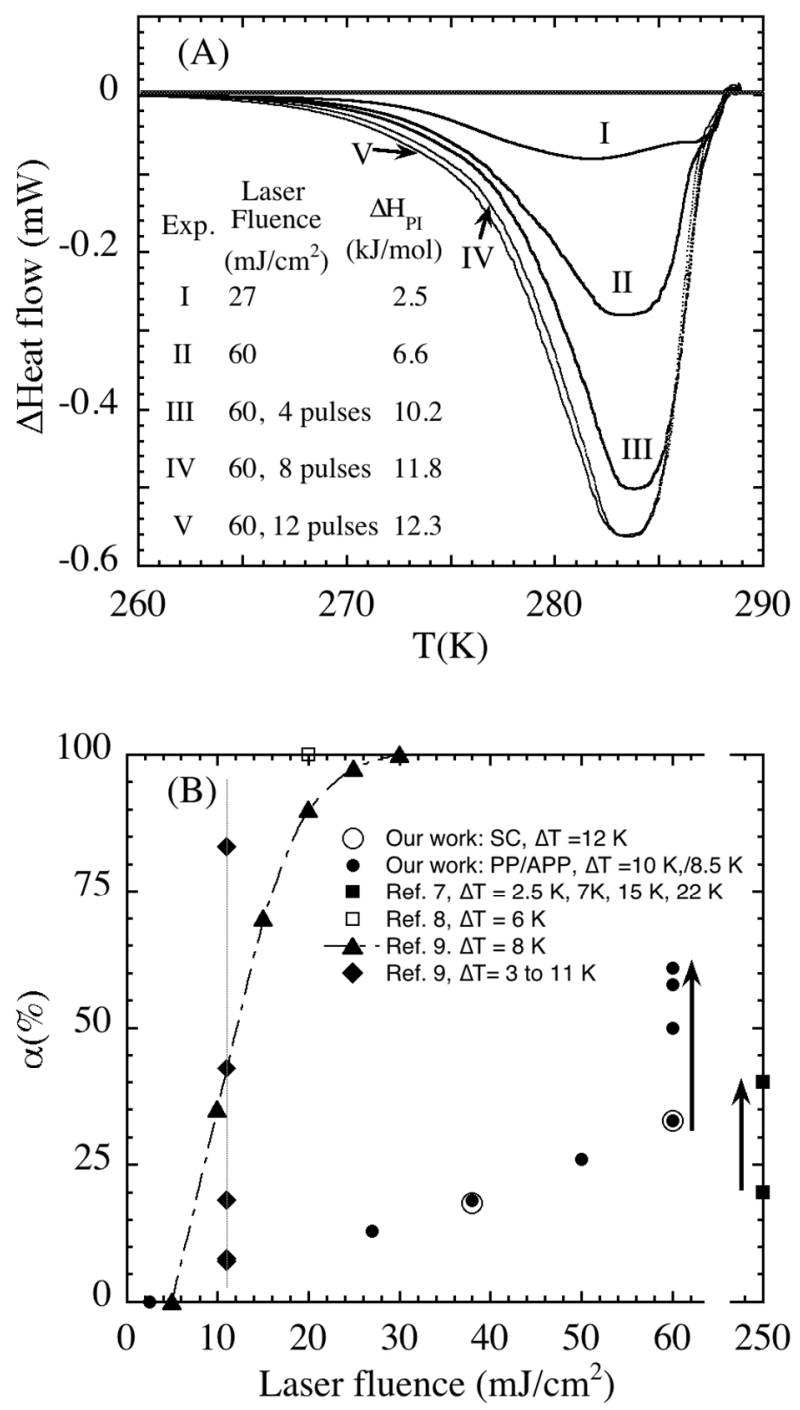

Figure 5. (A) Calorimetric anomalies for the PP sample after irradiation at $289.15 \mathrm{~K}$ (P1, 100\% LS state). Excess heat flow ( $\Delta$ Heat flow) after subtracting the corresponding background heat flow (BHF) for two laser fluencies (27 (I) and 60 (II) $\mathrm{mJ} / \mathrm{cm}^{2}$ ) and also for the case of 4(III), $8(\mathrm{IV})$ and 12 (V) consecutive pulses of $60 \mathrm{~mJ} / \mathrm{cm}^{2}$. (B) HS fraction induced by irradiation versus laser fluence on the compound 1. Experimental results from literature are also represented for comparison (see text). Arrows indicate the HS fraction increase when several laser pulses are applied consecutively. 
For the PP sample, no excitation is detected for a laser pulse of around $2.5 \mathrm{~mJ} / \mathrm{cm}^{2}$, but $\alpha$ reaches 0.13 and 0.33 for 27 and $60 \mathrm{~mJ} / \mathrm{cm}^{2}$ respectively with a good reproducibility. Consecutive pulses of $60 \mathrm{~mJ} / \mathrm{cm}^{2}$ allow increasing the photo-induced fraction up to a saturation value of 0.60 , for 12 successive pulses. Irradiation of the APP sample with pulses of 38,50 and $60 \mathrm{~mJ} / \mathrm{cm}^{2}$ resulted in slightly less efficient transformations than for the PP sample (ca. 30\%, see Figure S6), but these data, scaled to the PP values at $60 \mathrm{~mJ} / \mathrm{cm}^{2}$, actually follow the exact same trend as shown in Figure 5B where scaled data are depicted. The results for the SC sample are comparable since for 38 and $60 \mathrm{~mJ} / \mathrm{cm}^{2}, \alpha$ is 0.18 and 0.33 respectively (see supporting information, Figure S7). In order to check the consistency of our results, $\alpha$ has been additionally determined, for the latter case, by measuring a heating thermogram instead of a cooling one, since the calorimetric anomaly due to the transition from LS to HS after the irradiation must be smaller than the case without light excitation (see supporting information, Figure S8). In this case, $\alpha$ gives 0.28 , in agreement with the value obtained using the cooling procedure, 0.33 .

The photo-induced HS fractions obtained here are comparable to the first reported results with a polycrystalline sample ${ }^{7}$ where from the LS state and after irradiation with one single laser pulse with very large fluence of $250 \mathrm{~mJ} / \mathrm{cm}^{2}(\Delta T=2.5 \mathrm{~K})$, a HS fraction of 0.2 has been reached, 0.4 after a second pulse is applied. In our case, a laser fluence of only $40-60 \mathrm{~mJ} / \mathrm{cm}^{2}$ is required to reach a converted HS fraction of $0.2-0.3$, and successive pulses improve the overall conversion to 0.60 . On the contrary, in the original work, no further increment of the HS fraction was produced by additional pulses, but similar results were obtained with $\Delta T=7,15$ and $22 \mathrm{~K}$ performing the excitation with 10 successive pulses. ${ }^{7}$ However, the same group later reported a complete photo-conversion $^{8,9}$ for both polycrystalline $(\Delta T=8 \mathrm{~K})$ and single crystal $(\Delta T=6 \mathrm{~K})$ samples from the LS to the HS states using a single pulse and with only laser fluences above 20 
$\mathrm{mJ} / \mathrm{cm}^{2}$ and with a threshold value of $5 \mathrm{~mJ} / \mathrm{cm}^{2}$. Our experiments performed at $2.5 \mathrm{~mJ} / \mathrm{cm}^{2}$ agree with the presence of a threshold but do not reproduce this complete photo-conversion. A possible explanation may lie in the larger thickness of our polycrystalline sample since the radiation may not reach the whole sample and therefore cannot completely excite it. ${ }^{18}$ Another source of discrepancy may come from the determination of the laser fluences, which we determined here in-situ using the calorimeter (see Supplementary Information), while it is not described in the related reports. ${ }^{7-9}$

Another aspect relevant to the efficiency of the transformation lies in possible heating effects associated with the laser pulse and the energy deposited in the sample, as well as the thermal control of the used set-up during the photo-irradiation experiments. In fact, a large transient temperature jump, $\Delta \mathrm{T}_{\mathrm{h}}$, may occur, at least locally, and some authors have estimated it to be of some tens of degrees, therefore allowing to claim that heating mechanism plays a key role in the LS to HS conversion. ${ }^{16,18,19,21}$ Even in the case of a bistable system, such a transient temperature incursion may be large enough to allow the sample to reach or surpass the ascending branch of the hysteresis. To assess this possibility in our case, let us roughly evaluate the maximal transformed fraction, i.e. considering the minimal necessary $\Delta T_{\mathrm{h}}$, assuming the photo-induced effect is solely thermal and the whole pulse energy is invested to increase the temperature of the sample. Of course, this also has to involve the energy required to convert the LS species into HS ones and thus the total enthalpy associated with the transformation, $\Delta H_{\text {heating, }}$ (see Table 1 ) a term particularly important due to the first order character of the spin transition. This contribution has not been considered by some authors ${ }^{16,21}$ for the estimation of the temperature jump for first order spin transition and only the heat capacity term, enough in the case of second order transition $^{18,19,21}$, has been used. In our case, for a single pulse with a laser fluence of $60 \mathrm{~mJ} / \mathrm{cm}^{2}$ 
applied at $289.15 \mathrm{~K}$, the total amount of energy reaching the sample is $\mathrm{E}=17 \mathrm{~mJ}$, assuming that the sample is spread uniformly on the aluminium capsule (area $=\pi \cdot 0.3^{2}=0.283 \mathrm{~cm}^{2}$ ). For the PP sample, a $\Delta T_{\mathrm{h}}$ of $11 \mathrm{~K}$ would be sufficient to result in a full LS to HS transformation and $\Delta H_{\text {heating }}=44.34 \mathrm{~J} / \mathrm{g}$ (see Table 1 and using $435.3 \mathrm{~g} / \mathrm{mol}$ as molecular mass). Then considering a mean value of the heat capacity for this compound ${ }^{31}$ in the $270-320 \mathrm{~K}$ temperature range (excluding the transition temperature range) as $\mathrm{C}_{\mathrm{p}}=0.378 \mathrm{~J} / \mathrm{gK}$ and the simple relation $\mathrm{E}=$ $\mathrm{m}^{*} \cdot \mathrm{C}_{\mathrm{p}} \cdot \Delta T_{\mathrm{h}}+\mathrm{m}^{*} \cdot \Delta H_{\text {heating }}$ gives $\mathrm{m}^{*}=0.35 \mathrm{mg}$, that is at most $32 \%$ of the total PP sample mass ( $\mathrm{m}=1.10 \mathrm{mg}$ ) would be transformed with one laser pulse. At first the fact this estimated transformed fraction is close to the observed one, $33 \%$, seems to indicate a dominant role played by thermal effects. However, the calculation is made, neglecting optical transformation, and most of all without considering any heat transfer to the thermal bath, nor to the rest of the sample. A detailed evaluation of these effects requires analysing a complex thermal model, a task that is beyond this study. In our case, the heat transfer to the thermal bath is particularly relevant since the sample is in relatively good thermal contact with large masses of metallic parts (mainly the aluminium pan and also the sample support of the DSC oven), in addition maintained at constant temperature by the set-up. Actually, due to the laser pulse, only a small perturbation of the measured temperature well below $0.5 \mathrm{~K}$ is detected by the thermocouple located in the sample support and in contact with the bottom of the aluminium pan. This means that a significant fraction of the energy deposited in the sample by the laser pulse will not be invested in increasing the sample temperature. The typically low thermal conductivity of coordination compounds $^{32}$ also means that the propagation of the temperature increase within the sample will be slow, and thus allow for heat losses to the environment. Eventually, any portion of the sample suffering a smaller $\Delta T_{\mathrm{h}}$ will either transform only partially (if reaching the warming branch of 
the hysteresis loop) or not at all. Altogether, it therefore appears evident that the observed transformation of $33 \%$ can by no means be solely due to heating effect. This statement is also supported by the fact that similar transformed fractions are obtained when irradiating with a laser pulse of $60 \mathrm{~mJ} / \mathrm{cm}^{2}$ the APP sample at different temperatures $\left(\mathrm{P} 1^{*}, \mathrm{P} 2^{*}\right.$ and $\mathrm{P} 3^{*}$, that is $\Delta T=$ 8.5, 6.5 and $4.5 \mathrm{~K}$ respectively), while an increase would be expected upon reducing $\Delta T$ (i.e. performing the excitation closer to $T_{1 / 2 \text {, heating }}$ ) if the heating-induced mechanism would be dominant. Additionally, the saturation effect obtained using several pulses can be also explained by absorption and not only by thermal effects. ${ }^{15}$ Due to the fact the LS state has a higher absorption than the HS state for the excitation wavelength (see Figure S4), and as the LS species at the particle/sample surface decrease, the penetration increases and more HS species could be photo-induced until a saturation is reached when the intensity is reduced by the HS state absorption and no further excitation of LS can be induced. Therefore, while there is for sure some heating effect involved, it appears that the LS to HS conversion within the thermal hysteresis of $\left[\mathrm{Fe}(\right.$ pyrazine $\left.) \mathrm{Pt}(\mathrm{CN})_{4}\right]$ is not the (sole) result of a local heating due to the laser pulses used, in line with previous affirmations. ${ }^{7-9}$ Altogether our results are in agreement with the original data of ref 7 , but differ with the later reported results by the same authors (see Figure $5 \mathrm{~B})$ on the same compound ${ }^{9}$ and with those on $\left[\mathrm{Fe}(\mathrm{PM}-\mathrm{BiA})_{2}(\mathrm{NCS})_{2}\right]$ and $\left[\mathrm{Fe}\left(\mathrm{NH}_{2^{-}}\right.\right.$ trz $\left.)_{3}\right]\left(\mathrm{NO}_{3}\right)_{2} \cdot \mathrm{H}_{2} \mathrm{O}$ compounds ${ }^{5,15}$ where an increase of the high spin fraction as the excitation temperature increases has been determined. These discrepancies are striking, although a number of experimental conditions, some difficult to control or compare, may have a non-negligible effect, such as the material composition and properties, sample characteristics (crystallinity, crystallite size) or the thermal contacts and temperature controls. 
We have also investigated the excitation inside the hysteresis loop from the HS state using the same type of irradiation. In this case, the sample was cooled from room temperature (HS state) down to a temperature (P2-P5 in Figure 3A for PP sample, and SC2, SC3 for SC sample in Figure 3C) where the compound is still in the HS state or presents a HS-LS mixture state. Once the temperature is stable and controlled by the calorimeter, a laser pulse is applied to induce LS species. Subsequently, a heating thermogram is performed in order to detect a calorimetric anomaly due to the conversion of these LS species to a HS state. Because the energy of the pulse seems to be crucial in order to induce LS species, i.e high energetic pulses were not suitable to photo-induce them from the HS state because heating of the sample competes against the photoexcitation, ${ }^{8}$ we first performed the experiments using a low laser fluence of around $2.5 \mathrm{~mJ} / \mathrm{cm}^{2}$. As an example, Figure 6 shows one of these experiments performed in the PP sample. After the irradiation at P2 (see Figure 3A), only a very small anomaly is detected in the subsequent heating thermogram at around $300 \mathrm{~K}$ in agreement with the expected temperature range if some amount of LS species was induced and these were converted into HS species. However when the same experiment is performed without the application of the laser pulse, the calorimetric anomaly also appears with comparable enthalpy content, indicating that the LS photo-induced fraction is negligible. Similar result has been obtained for the SC sample when irradiation was performed at SC2 (see Figure 3C and supporting information Figures S9-S10). 


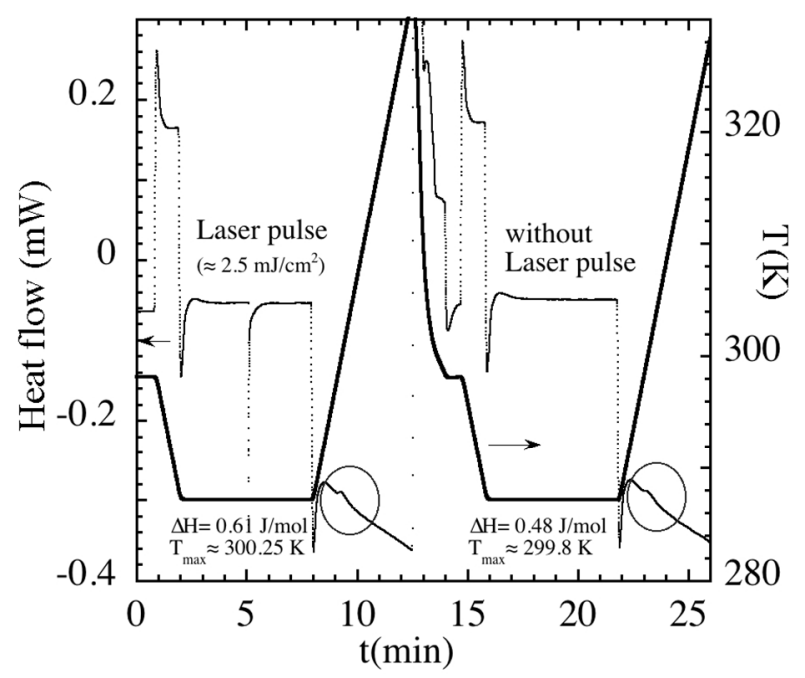

Figure 6. Calorimetric experiments corresponding to the irradiation at $287.15 \mathrm{~K}(\mathrm{P} 2)$ on PP sample using a low laser fluence $\left(2.5 \mathrm{~mJ} / \mathrm{cm}^{2}\right)$. Sample has been subjected to the same thermal history with and without irradiation. Similar anomaly is obtained in the subsequent heating indicating that no photo-induced LS species are produced.

This behaviour is in disagreement with ref. 8 where a complete HS to LS switch was induced. On the other hand, our results do agree with those reported in ref. 7 (our experimental conditions are similar to the experiment corresponding to point $\mathrm{H}$ of Figure 5 in this reference) where no excitation of LS species has been obtained from the HS state. The same behaviour has been obtained for the irradiation at P3, P4, P5 and SC3 (see supporting information, Figures S11-S15) where the excitation is performed in a LS-HS mixture state. This result also disagrees with ref 8, since when the irradiated state is a mixture of LS and HS species and a low power laser pulse is used some amount of photo-induced LS species is obtained. The fact that the enthalpy content of the detected calorimetric anomalies (equal with and without laser pulse) are larger as the temperature of irradiation is lower supports the thermal origin for these anomalies and reflects the conversion of the pre-existing LS species at the irradiation temperature to the HS state. The 
use of large energetic pulses $\left(16,27\right.$ and $60 \mathrm{~mJ} / \mathrm{cm}^{2}$ at P3, P4 and SC2 respectively) was also tested but does not allow inducing a detectable amount of LS species. The present calorimetric study therefore evidences that no HS to LS optical conversion can be obtained as the result of nanosecond-pulsed green laser irradiation, in agreement with the absence of absorption band in this range of wavelengths. The previously detected presence of LS species under similar conditions most likely arises from thermally converted centres due to the closeness of the experiment temperature to the thermal conversion. Here, it is interesting to note that Hauser et al have recently produced an efficient HS to LS switching (reverse-LIESST) in in the vicinity of the thermal transition of the $\left[\mathrm{Fe}(\mathrm{ptz})_{6}\right]\left(\mathrm{BF}_{4}\right)_{2}$ spin crossover compound (ptz $=1$-propyl-tetrazole) using an adequate wavelength of $830 \mathrm{~nm}$, and unravelling the role of ligand-field states in the ultrafast photophysical cycle of this specific compound. ${ }^{33}$

In order to evaluate the influence of the initial state on the LS to HS excitation process, experiments were repeated starting from a thermally induced HS/LS mixed state instead of a full LS state. For this, the APP sample is first heated from the LS state up to $298.15 \mathrm{~K}$ reaching a HS/LS mixed state with $\alpha=0.6$ according to the hysteresis loop (Figure 3B). After the sample temperature is decreased down to $289.15 \mathrm{~K}$ ( $\mathrm{P} 4 *$ in Figure $3 \mathrm{~B})$, a pulse of $60 \mathrm{~mJ} / \mathrm{cm}^{2}$ is applied, and a thermogram is performed on cooling, allowing the corresponding anomaly to be recorded. The experiment following the same thermal history, but without the application of the pulse, has also been performed for comparison. The results are shown in Figure 7A together with the peak corresponding to the complete HS $\rightarrow$ LS transition. Without pulse, an anomaly centred at $285 \mathrm{~K}$ is obtained with a low temperature tail down to $270 \mathrm{~K}$. The peak is significantly shifted to higher temperature than the peak corresponding to the complete HS $\rightarrow$ LS transition in agreement with the expected behaviour when a minor loop is followed, and thus consistent with the formation of 
independent domains. ${ }^{34}$ Additionally, considering the enthalpy content we can estimate a high spin fraction of 0.56 in agreement with the expected value at $298.15 \mathrm{~K}$ from the heating branch of the hysteresis loop. The excitation changes the profile of the peak increasing the tail and decreasing the contribution at higher temperature. In this case, we can evaluate $\alpha=0.69$, then an increase of 0.13 has been induced by the irradiation which is lower than the value obtained by the same pulse performed on the $100 \%$ LS state and at the same temperature. The same experiment was repeated with 4 pulses and again the profile of the peak was modified showing a larger tail at low temperature corresponding to a prominent peak and a decrease of the peak at high temperature with a maximum temperature shifted to lower temperature. The HS fraction increase was only $18 \%$ smaller than the $50 \%$ achieved from the $100 \%$ LS state.

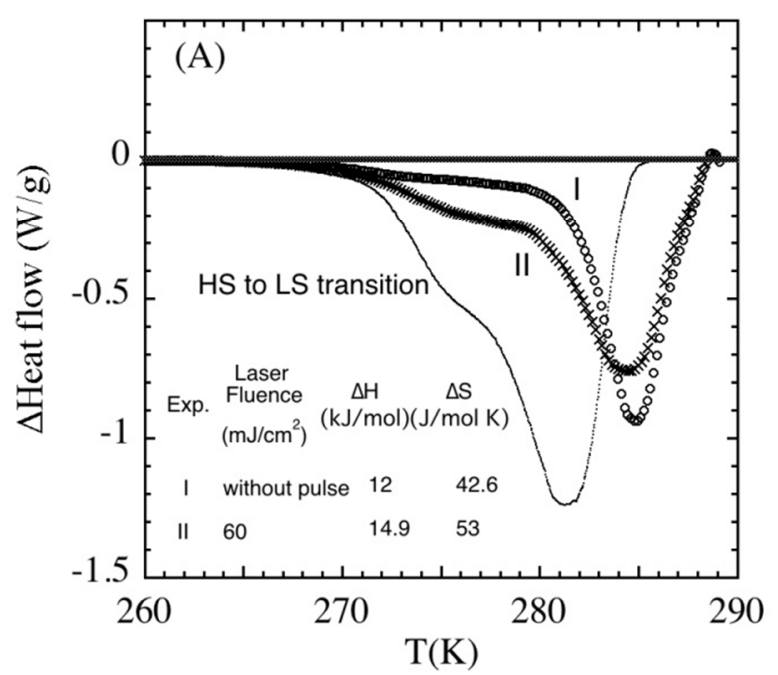




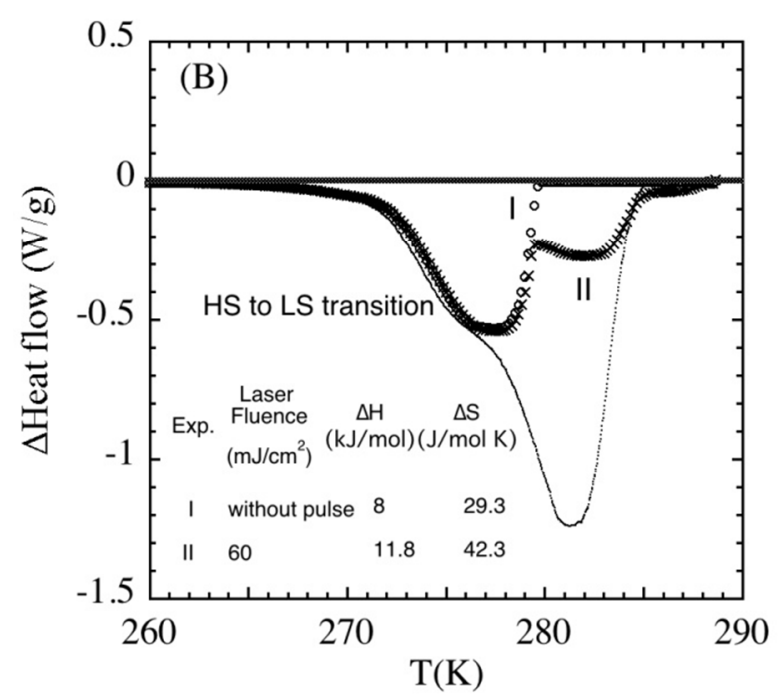

Figure 7: Anomalies (crosses) obtained on cooling after excitation with a laser pulse of 60 $\mathrm{mJ} / \mathrm{cm}^{2}$ at $289.15 \mathrm{~K}$ from a HS/LS mixed state reached, as it is explained in the text, from the $100 \%$ LS (A) and 100\% HS (B) state. The complete HS to LS transition (small dots) and the anomalies obtained following the same thermal history but without laser pulse (open circles) are also shown for comparison (see text).

We have then performed the same type of experiment but creating the HS/LS mixed state from the pure HS, i.e. by cooling the sample from the HS state down to $280.15 \mathrm{~K}(\alpha=0.55$ from the cooling branch of the hysteresis loop in figure 3B), then heating up to $289.15 \mathrm{~K}$ (P5* in Figure 3B), irradiating with a laser pulse of $60 \mathrm{~mJ} / \mathrm{cm}^{2}$, and recording a thermogram on cooling. The same thermal process was repeated but without the application of the pulse in order to have a reference baseline. The latter, shown in Figure 7B, presents an anomaly starting at around $280 \mathrm{~K}$ as expected and matches perfectly the low temperature part of the peak corresponding to the complete HS to LS transition. This anomaly corresponds to the final conversion of the remaining HS species. Considering its enthalpy content (Figure 7B), the converted HS fraction was 0.35, lower than the expected value of 0.55 . This can be due to a relaxation process of the HS centres 
to the ground LS state, similar to the case of the $\left[\mathrm{Fe}\left(\mathrm{H}_{4} \mathrm{~L}\right)_{2}\right]\left(\mathrm{ClO}_{4}\right)_{2} \cdot \mathrm{H}_{2} \mathrm{O} \cdot 2\left(\mathrm{CH}_{3}\right)_{2} \mathrm{CO} \mathrm{SCO}$ compound. ${ }^{10}$ Irradiation modifies this anomaly, shown also in Figure 7B, and a new peak appears at the high temperature side and also reproduces the peak obtained without the application of the pulse. Both anomalies are perfectly delimited by the peak corresponding to the $100 \%$ HS to LS transition. The mixed HS/LS state reached corresponds to $\alpha=0.52$, then the increase due to the irradiation is 0.17 which is slightly higher than the HS fraction increase from the HS/LS mixed state reached through the heating branch but still significantly lower than the value reached from the full LS state corresponding to $\alpha=0.26$. However, when the excitation is performed at the same temperature on a similar HS/LS mixed state obtained previously by irradiation (P1 in Figure $3 \mathrm{~A}$ and after four pulses a HS fraction of 0.5 is reached from the $100 \% \mathrm{LS}$ state close to the previous thermally induced mixed HS/LS state) the increase of the HS fraction by four additional consecutive pulses was only 0.08. It thus appears that irradiation from a thermally induced mixed HS/LS state from either HS and LS state is less efficient than from a pure LS state but more efficient than from a similar mixed HS/LS state reached by irradiation.

\section{CONCLUSIONS}

In summary, the optical switching from LS to HS state of the $\left[\mathrm{Fe}(\mathrm{pz}) \mathrm{Pt}(\mathrm{CN})_{4}\right] \mathrm{SCO}$ material through single and multiple green $(\lambda=532 \mathrm{~nm})$ nanosecond-laser pulse(s) has been confirmed and accurately evaluated using calorimetry, a complement to the Raman spectroscopy only results previously reported. A maximum conversion of $60 \%$ has been obtained by successive pulses, likely limited by the penetration depth of light within the sample/crystallites. Besides, the results seem to indicate that, although thermal effects may be present, the LS to HS transformation is not the sole consequence of such effects. On the other hand, the reverse 
transformation, HS to LS, previously reported to be induced at the same wavelength, has not been observed, and evidence is given here that such transformation is likely the result of thermal effects and/or relaxation of the HS species, due to the closeness of the temperature experiments to the cooling branch of the thermal SCO hysteresis. Finally, conversion starting from a thermally induced LS/HS mixed state is found to be less efficient than from a pure LS state, however the mixed LS/HS state is created, i.e. either from the pure HS or LS state although more efficient than from a similar mixed LS/HS state obtained by irradiation. This work highlights the great potential of photo-calorimetry to study switching of cooperative SCO materials within their bistability domain.

\section{AUTHOR INFORMATION \\ Corresponding Author \\ *E-mail: mcastro@unizar.es}

\section{Notes}

LPL and JAR synthesized the materials. JARV, OR and MC realized the experiments. The manuscript was written by OR and MC with contributions from all authors. All authors have given approval to the final version of the manuscript. The authors declare no competing financial interests.

\section{ACKNOWLEDGMENT}


This work has been supported by the Spanish MINECO and European Commission FEDER under projects MAT2011-24284, MAT2011-27233-C02-02, CTQ2011-23862-C02-01, CSD2007-00010 and CTQ2013-46275-P, by the Gobierno de Aragón through grants E98"MOLCHIP" and E100-"Propiedades Térmicas de Materiales" and by the Generalitat Valenciana through PROMETEO/2012/049. L.P.L. thanks the Generalitat Valenciana for a predoctoral fellowship in the frame of the project PROMETEO/2012/049. JARV acknowledges CSIC for a JAE-doc contract. The authors acknowledge the use of the Physical measurements and X-ray diffraction units of Servicio General de Apoyo a la Investigación-SAI, Universidad de Zaragoza and of the differencial scanning calorimeter Q1000 of Servicio de análisis térmico y calorimetría del Instituto de Ciencia de Materiales de Aragón (ICMA).

\section{ASSOCIATED CONTENT}

Supporting Information Available: Determination of the laser fluences. Temperature dependence of the magnetic properties of the SC sample of 1. Visible absorption spectra of powder sample for the LS and HS state. Crystallographic data and refinement details of $\mathbf{1}$ at 310 and $240 \mathrm{~K}$. Selected calorimetric experiments with irradiation. This material is available free of charge via the Internet http://pubs.acs.org.

\section{REFERENCES}

(1) Sato, O.; Tao, J.; Zhang, Y.Z. Control of Magnetic Properties through External Stimuli. Angew. Chem. Int. Ed. 2007, 46, 2152-2187. 
(2) Bousseksou, A.; Molnár, G.; Matouzenko, G. Switching of Molecular Spin State in Inorganic Complexes by Temperature, Pressure, Magnetic Field and Light: Towards Molecular Devices. Eur. J. Inorg. Chem. 2004, 4353-4369.

(3) Bousseksou, A.; Molnár, G.; Salmon, L.; Nicolazzi, W. Molecular Spin Crossover Phenomenon: Recent Achievements and Prospects. Chem. Soc. Rev. 2011, 40, 3313-3335.

(4) Hauser, A. Light-Induced Spin Crossover and the High-Spin Low-Spin Relaxation. Top. Curr. Chem. 2004, 234, 155-198

(5) Freysz, E.; Montant, S.; Létard, S.; Létard, J-F. Single Laser Pulse Induces Spin State Transition within the Hysteresis Loop of an Iron Compound. Chem. Phys. Lett. 2004, 394, 318323.

(6) Liu, H.; Fujishima, A.; Sato, O. Photoinduced Phase Transition in an Iron (II) SpinCrossover Complex with a $\mathrm{N}_{3} \mathrm{O}_{2}$ Macrocyclic Ligand. Appl. Phys. Lett. 2005, 86, 122511.

(7) Bonhommeau, S.; Molnár, G.; Galet, A.; Zwick, A.; Real, J.A.; McGarvey, John J.; Bousseksou, A. One Shot Laser Pulse Induced Reversible Spin Transition in the Spin-Crossover Complex $\left[\mathrm{Fe}\left(\mathrm{C}_{4} \mathrm{H}_{4} \mathrm{~N}_{2}\right)\left\{\mathrm{Pt}(\mathrm{CN})_{4}\right\}\right]$ at Room Temperature. Angew. Chem. Int. Ed. 2005, 44, 40694073.

(8) Cobo, S.; Ostrovskii, D.; Bonhommeau, S.; Vendier, L.; Molnár, G.; Salmon, L.; Tanaka, K.; Bousseksou, A. Single-Laser-Shot-Induced Complete Bidirectional Spin Transition at Room Temperature in Single Crystals of $\left(\mathrm{Fe}^{\mathrm{II}}(\right.$ pyrazine $\left.)\left(\mathrm{Pt}(\mathrm{CN})_{4}\right)\right)$. J. Am. Chem. Soc. 2008, 130, 90199024. 
(9) Bonhommeau, S.; Molnár, G.; Cobo, S.; Ostrovskii, D.; Bousseksou, A. One Laser Shot Induces Complete Phase Transition in the Spin Crossover Complex Fe(pyrazine)[Pt(CN) $\left.{ }_{4}\right]$. Polyhedron 2009, 28, 1610-1613.

(10) Craig G.A.; Sánchez Costa J.; Roubeau O.; Teat S.J.; Shepherd H.J.; Lopes M.; Molnár G.; Bousseksou A.; Aromí G. High-Temperature Photo-Induced Switching and PressureInduced Transition in a Cooperative Molecular Spin-Crossover Material. Dalton Transactions 2014, 43, 729-737.

(11) Roubeau, O. Triazole-Based One-Dimensional Spin-Crossover Coordination Polymers. Chem. Eur. J. 2012, 18, 15230-15244

(12) Moussa, N. O.; Ostrovskii, D.; Martinez Garcia, V.; Molnár, G.; Tanaka, K.; Gaspar, A.B.; Real, J.A.; Bousseksou, A. Bidireccional Photo-Switching of the Spin State of Iron (II) Ions in a Triazol Based Spin Crossover Complex within the Thermal Hysteresis Loop. Chem. Phys. Lett. 2009, 477, 156-159.

(13) Fouché O.; Degert J.; Jonusauskas G.; Baldé C.; Desplanche C.; Létard J.F.; Freysz E. Laser Induced Spin State Transition: Spectral and Temporal Evolution. Chem. Phys. Lett. 2009, 469, 274-278.

(14) Gallé, G.; Deldicque, D.; Degert, J.; Forestier, T.; Létard, J-F.; Freysz, E. Room Temperature Study of the Optical Switching of a Spin Crossover Compound inside Its Thermal Hysteresis Loop. Appl. Phys. Lett. 2010, 96, 041907.

(15) Gallé, G.; Degert, J.; Mauriac, C.; Etrillard, C.; Létard, J-F. ; Freysz, E. Nanosecond Study of Spin State Transition Induced by a Single Nanosecond Laser Shot on $\left[\mathrm{Fe}\left(\mathrm{NH}_{2} \operatorname{trz}\right)_{3}\right]$ 
Compounds inside and outside Their Thermal Hysteresis Loops. Chem. Phys. Lett. 2010, 500, 18-22.

(16) Fouché, O.; Degert, J.; Jonusauskas, G.; Daro, N.; Létard, J-F.; Freysz, E. Mechanism for Optical Switching of the Spin Crossover $\left[\mathrm{Fe}\left(\mathrm{NH}_{2} \text {-trz }\right)_{3}\right](\mathrm{Br})_{2} \cdot 3 \mathrm{H}_{2} \mathrm{O}$ Compound at Room Temperature. Phys. Chem. Chem. Phys. 2010, 12, 3044-3052.

(17) Guillaume F., Tobon Y.A., Bonhommeau S., Létard J.F., Moulet L., Freysz E. Photoswitching of the Spin Crossover Polymeric Material [Fe $\left.(\mathrm{Htrz})_{2}(\operatorname{trz})\right]\left(\mathrm{BF}_{4}\right)$ under Continuous Laser Irradiation in a Raman Scattering Experiment. Chem. Phys. Lett. 2014, 604, 105-109.

(18) Lorenc M.; Hébert J.; Moisan N.; Trzop E.; Servol M.; Buron-Le Cointe M.; Cailleau H.; Boillot M.L.; Pontecorvo E.; Wulff M.; et al. Successive Dynamical Steps of Photoinduced Switching of a Molecular Fe(III) Spin-Crossover Material by Time-Resolved X-Ray Diffraction. Phys. Rev. Lett. 2009, 103, 028301-1-4. Note that a finite penetration depth of the order of tens of microns has been considered in this work.

(19) Lorenc M.; Balde Ch.; Kaszub W.; Tissot A.; Moisan N.; Servol M.; Buron-Le Cointe M.; Cailleau H.; Chasle P.; Czarnecki P.; et al. Cascading Photo-induced, Elastic and Thermal Switching of Spin States Trigerred by a Femtosecond Laser Pulse in an Fe(III) Molecular Crystal. Phys. Rev. B 2012, 85, 054302.

(20) Tissot A.; Bertoni R.; Collet E.; Toupet L.; Boillot M.-L. The Cooperative Spin-State Transition of a Iron (III) Compound $\left.\left[\mathrm{Fe}^{\mathrm{III}} \text { (3-MeO-SalEen) }\right)_{2}\right] \mathrm{PF}_{6}$ : Thermal- vs. Ultra-Fast PhotoSwitching. J. Mater. Chem. 2011, 21, 18347. 
(21) Bertoni R.; Lorenc M.; Tissot A. ; Boillot M.-L. ; Collet E. Femtosecond Photo-Switching Dynamics and Microsecond Thermal Conversion Driven by Laser Heating in Fe ${ }^{\mathrm{III}}$ SpinCrossover Solids. Coord. Chem. Rev. 2015, 282-283, 66-76.

(22) Bedoui S.; Lopes M.; Nicolazzi W.; Bonnet S.; Zheng S.; Molnár G.; Bousseksou A. Triggering a Phase Transition by a Spatially Localized Laser Pulse: Role of the Strain. Phys. Rev. Lett. 2012, 109, 135702.

(23) Niel, V.; Martinez-Agudo, J.M.; Muñoz, M.C.; Gaspar, A.B.; Real, J.A. Cooperative Spin Crossover Behavior in Cyanide-Bridged Fe(II)-M(II) Bimetallic 3D Hofmann-Like Networks (M = Ni, Pd and Pt). Inorg. Chem. 2001, 40, 3838-3839.

(24) CrysAlis Pro: Agilent Technologies XRD Products. Yarnton, U.K.; 2012.

(25) Altomare, A.; Burla, M. C.; Camalli, M.; Cascarano, G. L.; Giacovazzo, C.; Guagliardi, A.; Moliterni, A. G. G.; Polidori, G.; Spagna, R. SIR97: A New Tool for Crystal Structure Determination and Refinement. J. Appl. Cryst. 1999, 32, 115-119.

(26) Sheldrick, G.M. Crystal Structure Refinement with SHELXL. Acta Cryst. 2015, C71, 3-8.

(27) Sheldrick, G.M. SHELXTL Bruker AXS Inc., Madison, WI, USA; 2001

(28) Tayagaki, T.; Galet, A.; Molnár, G.; Muñoz, M.C.; Zwick, A.; Tanaka, K.; Real, J.A.; Bousseksou, A. Metal Dilution Effects on the Spin-Crossover Properties of the ThreeDimensional Coordination Polymer Fe(pyrazine) $\left[\mathrm{Pt}(\mathrm{CN})_{4}\right]$. J. Phys. Chem. B 2005, 109, 1485914867.

(29) Ohba, M.; Yoneda, K.; Agustí, G.; Muñoz, M.C.; Gaspar, A.B.; Real, J.A.; Yamasaki, M.; Ando, H; Nakao, Y.; Sakaki, S.; et al. Bidirectional Chemo-Switching of Spin State in a 
Microporous Framework. Angew. Chem., Int. Ed. 2009, 48, 4767-4771. Agustí, G.; Ohtani, R.; Yoneda, K.; Gaspar, A.B.; Ohba, M.; Sánchez-Royo, J.F.; Muñoz, J.F.; Kitagawa, S; Real, J.A. Oxidative Addition of Halogens on Open Metal Sites in a Microporous Spin-Crossover Coordination Polymer. Angew. Chem., Int. Ed. 2009, 48, 8944-8947.

(30) Rodríguez-Velamazán, J.A.; González, M.A.; Real J.A.; Castro, M.; Muñoz, M.C.; Gaspar, A.B.; Ohtani, R.; Ohba, M.; Yoneda, K.; Hijikata, Y.; et al. A switchable Molecular Rotator: Neutron Spectroscopy Study on a Polymeric Spin-Crossover Compound. J. Am. Chem. Soc. 2011, 134, 5083-5089.

(31) Palacios E., Private Communication. Heat Capacity of the $\left[\mathrm{Fe}(\right.$ pyrazine $\left.)\left(\mathrm{Pt}(\mathrm{CN})_{4}\right)\right]$ Compound Measured by Adiabatic Calorimetry. 2015.

(32) Jacobi, R.; Romstedt, H.; Spiering, H.; Gütlich, P. Microcalorimetry of the SpinTransition Systems $\left[\mathrm{Fe}(\text { bts })_{2}(\mathrm{NCS})_{2}\right]$ and $\left[\mathrm{Fe}(2-\text { pic })_{3}\right] \mathrm{Cl}_{2} \cdot \mathrm{EtOH}$ in the Range $15 \mathrm{~K}<\mathrm{T}<300 \mathrm{~K}$. Angew. Chem. Int. Ed. Engl. 1992, 31, 178-180.

(33) Marino, A.; Chakraborty, P.; Servol, M.; Lorenc, M.; Collet, E.; Hauser, A. The Role of Ligand-Field States in the Ultrafast Photophysical Cycle of the Prototypical Iron (II) SpinCrossover Compound $\left[\mathrm{Fe}(\mathrm{ptz})_{6}\right]\left(\mathrm{BF}_{4}\right)_{2}$. Angew. Chem. Int. Ed. 2014, 53, 3863-3867.

(34) König, E.; Ritter, G.; Kulshreshtha, S. K. The Nature of Spin-State Transition in Solid Complexes of Iron (II) and the Interpretation of Some Associated Phenomena. Chem. Rev. 1985, 85, 219-234; König, E.; Kanellakopulos, B.; Powietzka, B.; Goodwin, H. A. Detailed Study of the Hysteresis Associated with the Spin-State Transition in Bis(2,6-bis(pyrazol-3-yl) pyridine) Iron (II) bis(tetrafluoroborate) and the Hypothesis of Independent Domains. Inorg. Chem. 1989, 28, 3993-3996; König, E.; Kanellakopulos, B.; Powietzka, B.; Goodwin, H. A. Detailed 
Hysteresis Studies and Nature of the Spin-State Transition in bis(1,10-phenanthroline-2carbaldehyde phenylhydrazone) Iron (II) Complexes. Inorg. Chem. 1990, 29, 4944-4949; Constant-Machado, H.; Stancu, A.; Linarès, J.; Varret, F. Thermal Hysteresis Loops in SpinCrossover Compounds Analyzed in terms of Classical Preisach Model. IEEE Trans. Magnetics 1998, 34, 2213-2219. 


\section{TOC GRAPHICS}

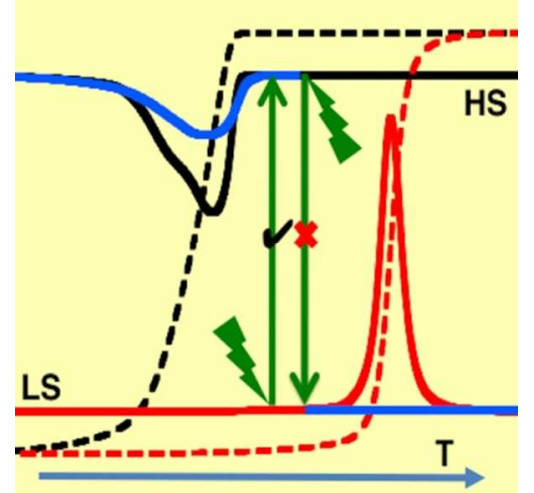

19

20

21

22

23

24

25

26

27

28

29

30

31

32

33

34

35

36

37

38

39

40

41

42

43

44

45

46

47

48

49

50

51

52

53

54

55

56

57

58

59

60

ACS Paragon Plus Environment 


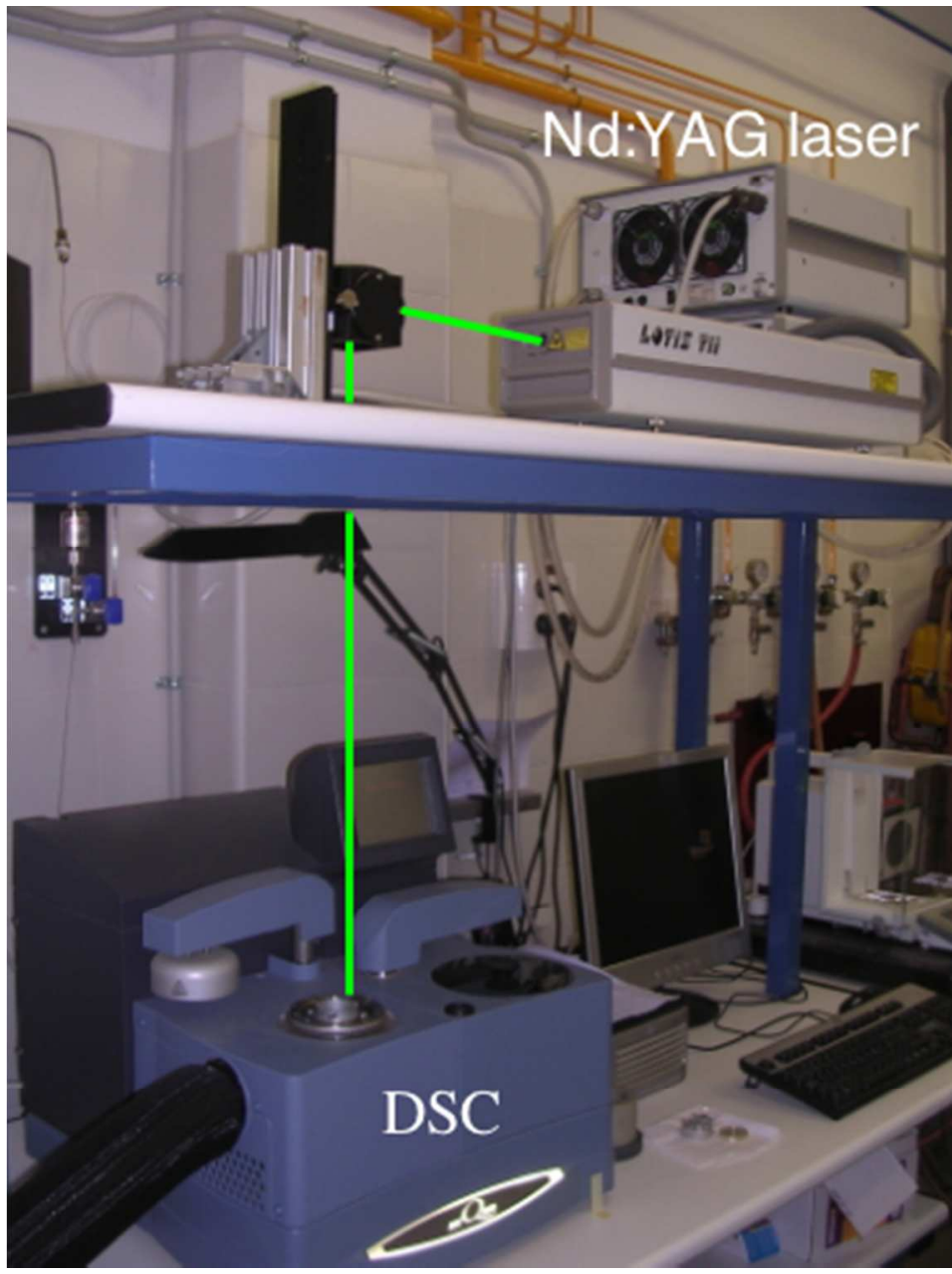

$75 \times 100 \mathrm{~mm}(123 \times 123 \mathrm{DPI})$ 


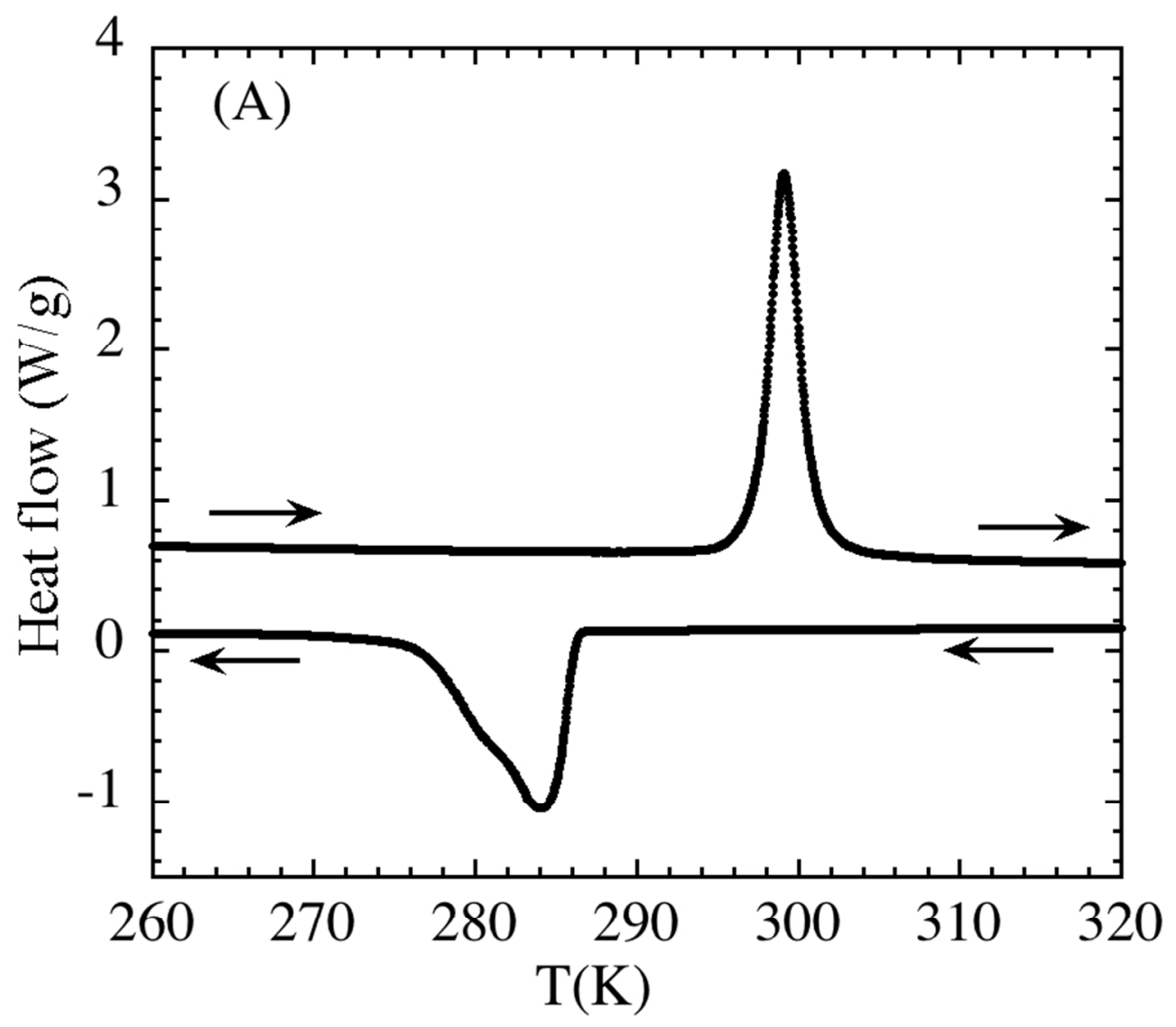

$80 \times 70 \mathrm{~mm}(288 \times 288$ DPI $)$ 


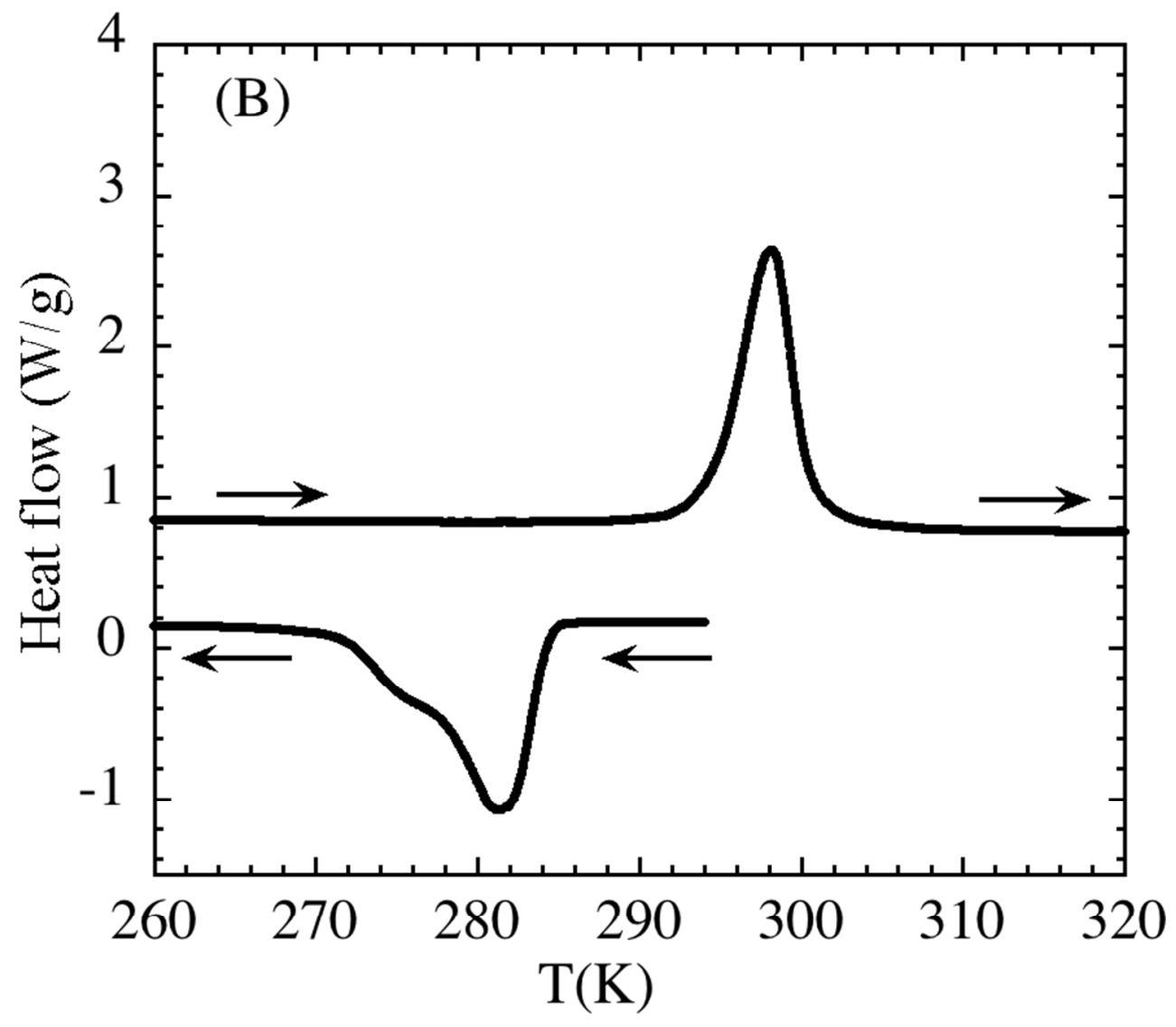

$80 \times 70 \mathrm{~mm}(288 \times 288$ DPI $)$ 


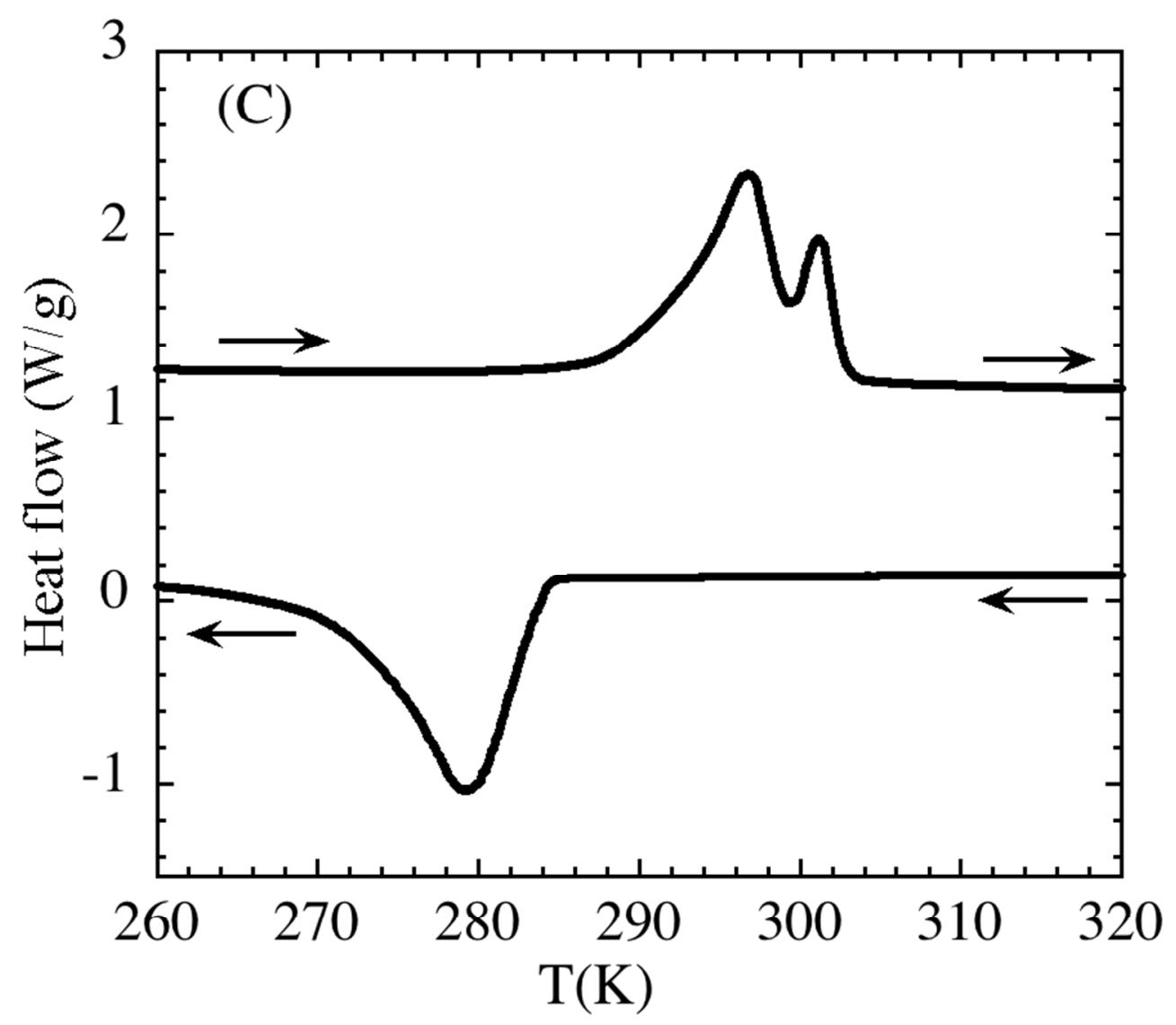

$80 \times 70 \mathrm{~mm}(288 \times 288$ DPI $)$ 


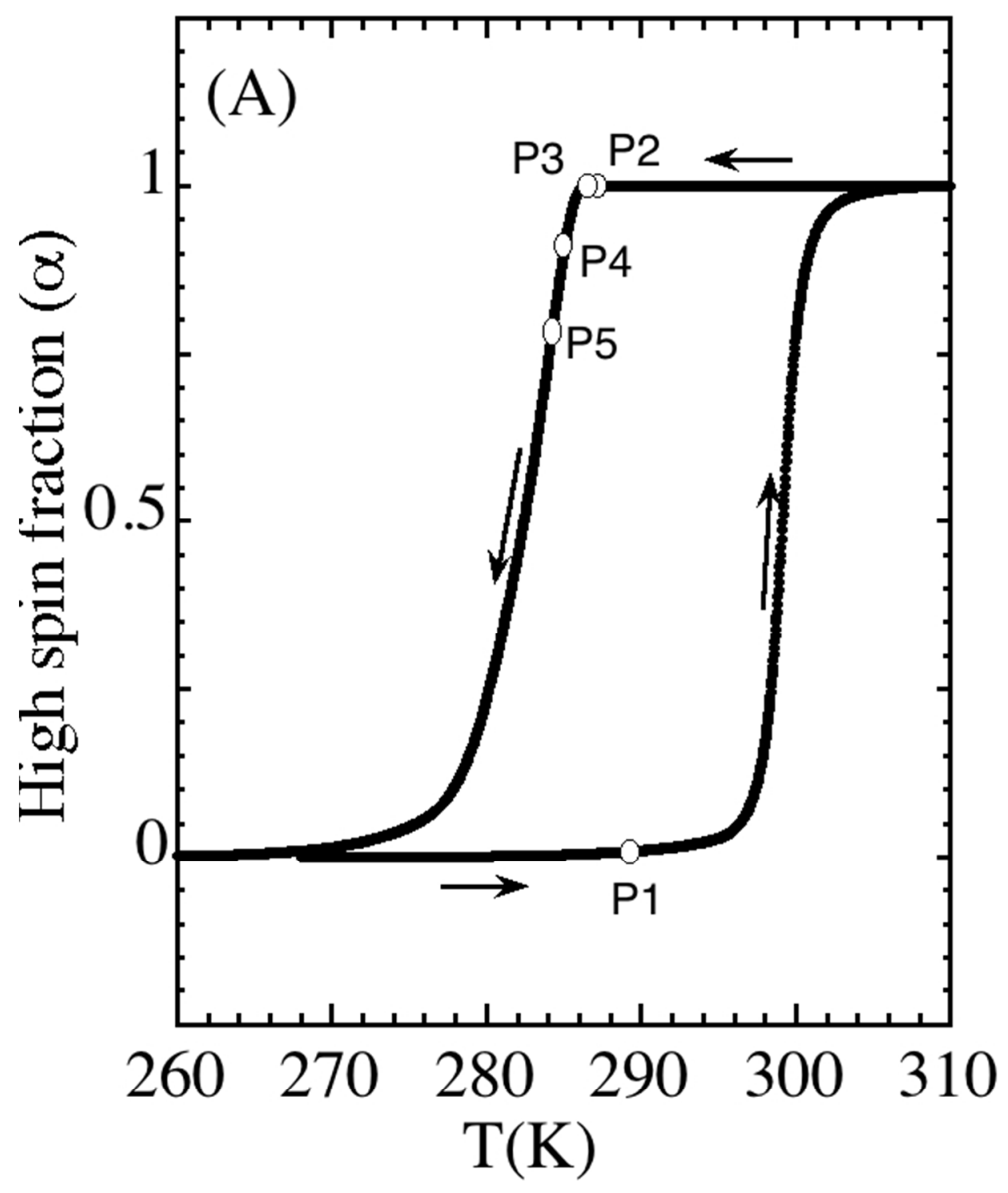

$55 \times 70 \mathrm{~mm}(288 \times 288 \mathrm{DPI})$ 


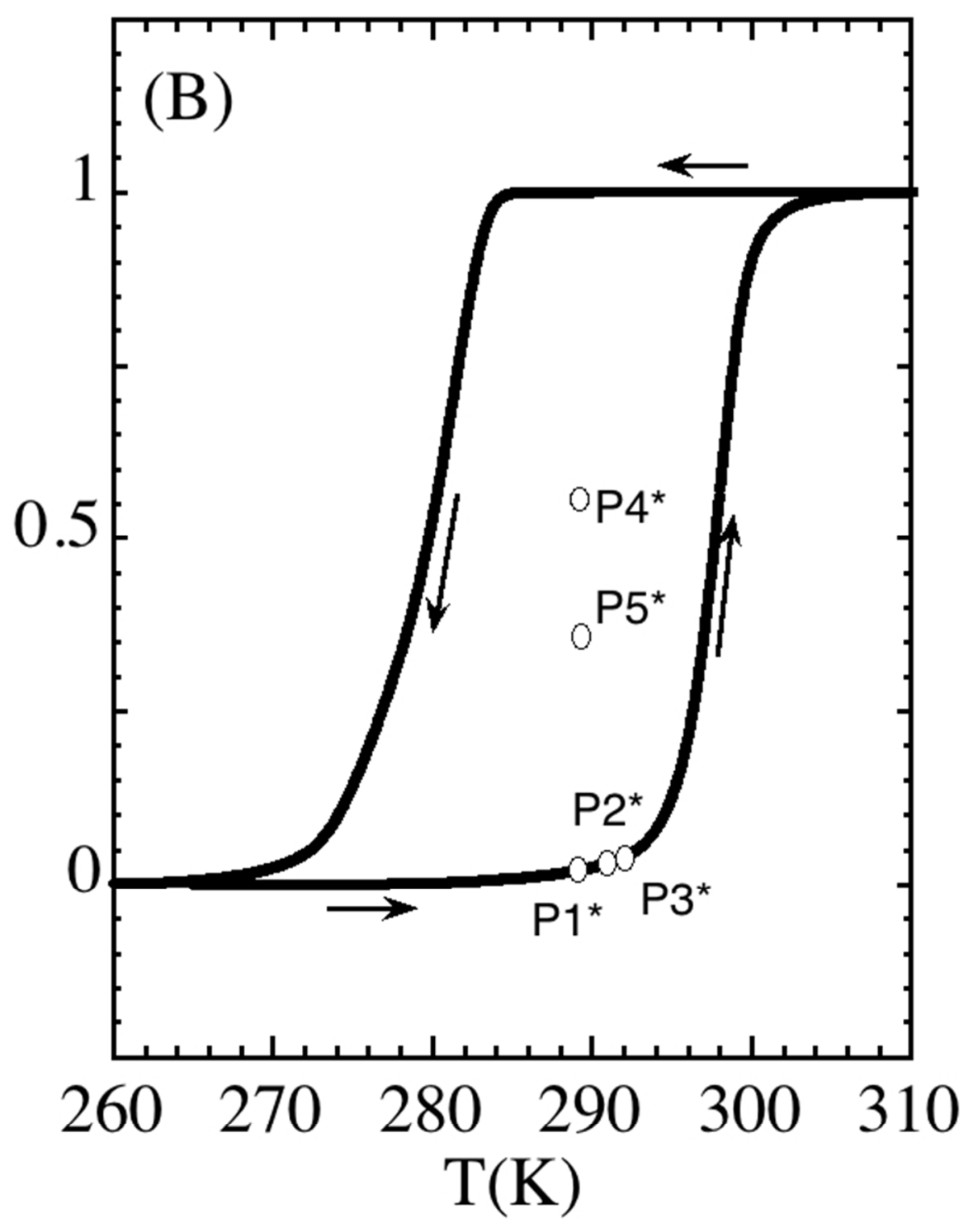

$55 \times 70 \mathrm{~mm}(288 \times 288 \mathrm{DPI})$ 


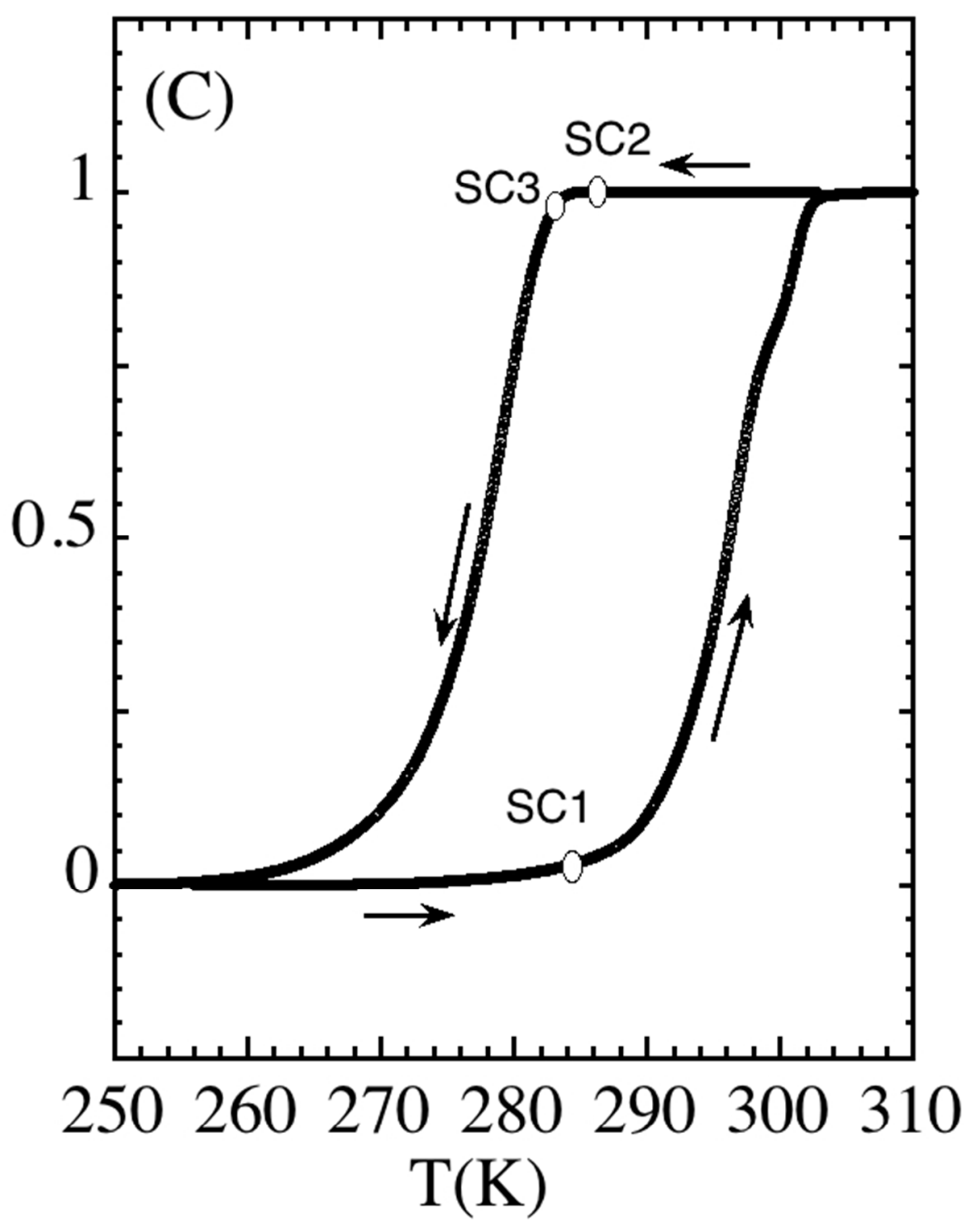

$55 \times 70 \mathrm{~mm}(288 \times 288 \mathrm{DPI})$ 


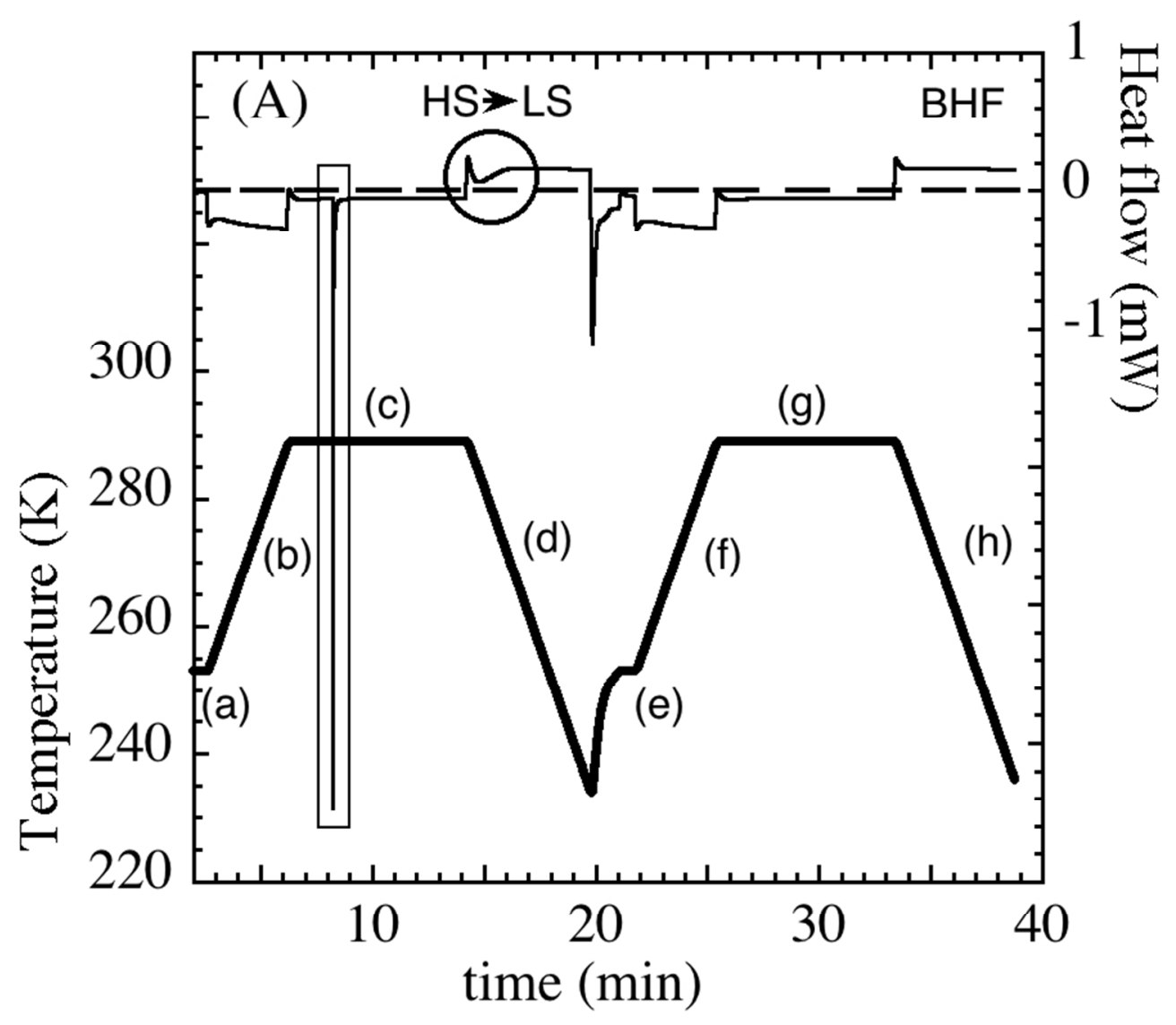

$80 \times 70 \mathrm{~mm}(288 \times 288$ DPI $)$ 


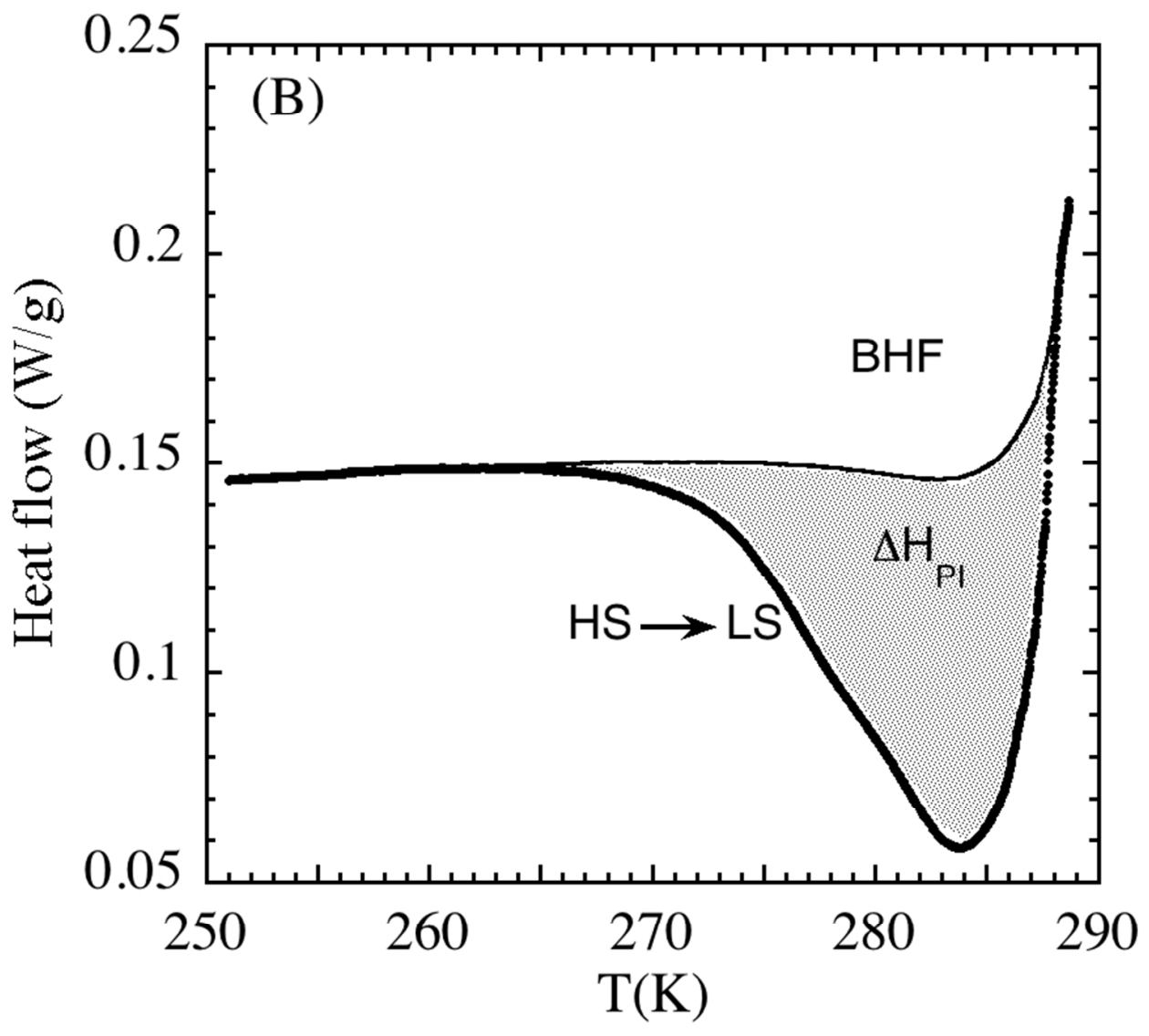

$80 \times 70 \mathrm{~mm}(288 \times 288$ DPI $)$ 


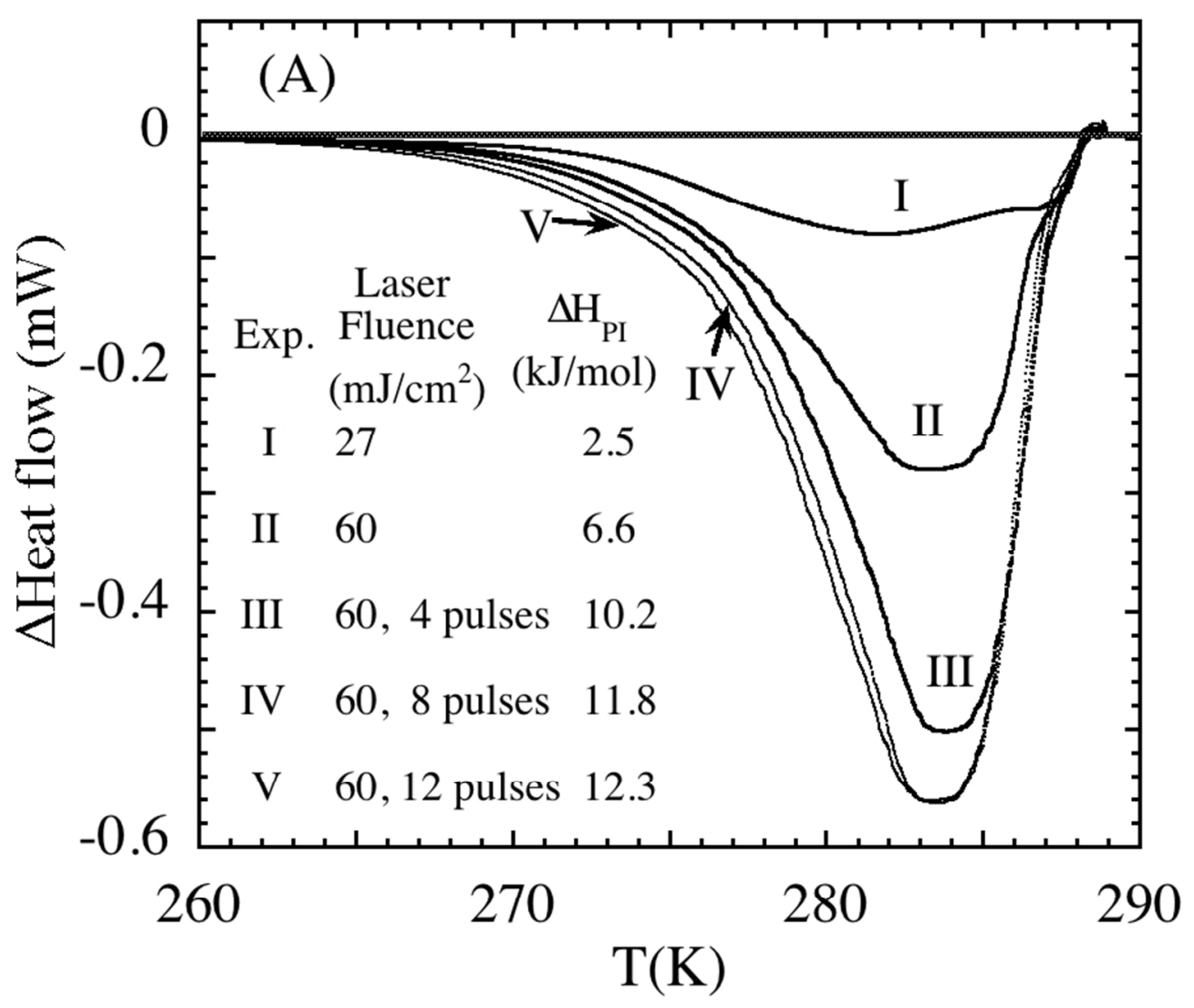

$80 \times 70 \mathrm{~mm}(288 \times 288$ DPI $)$ 


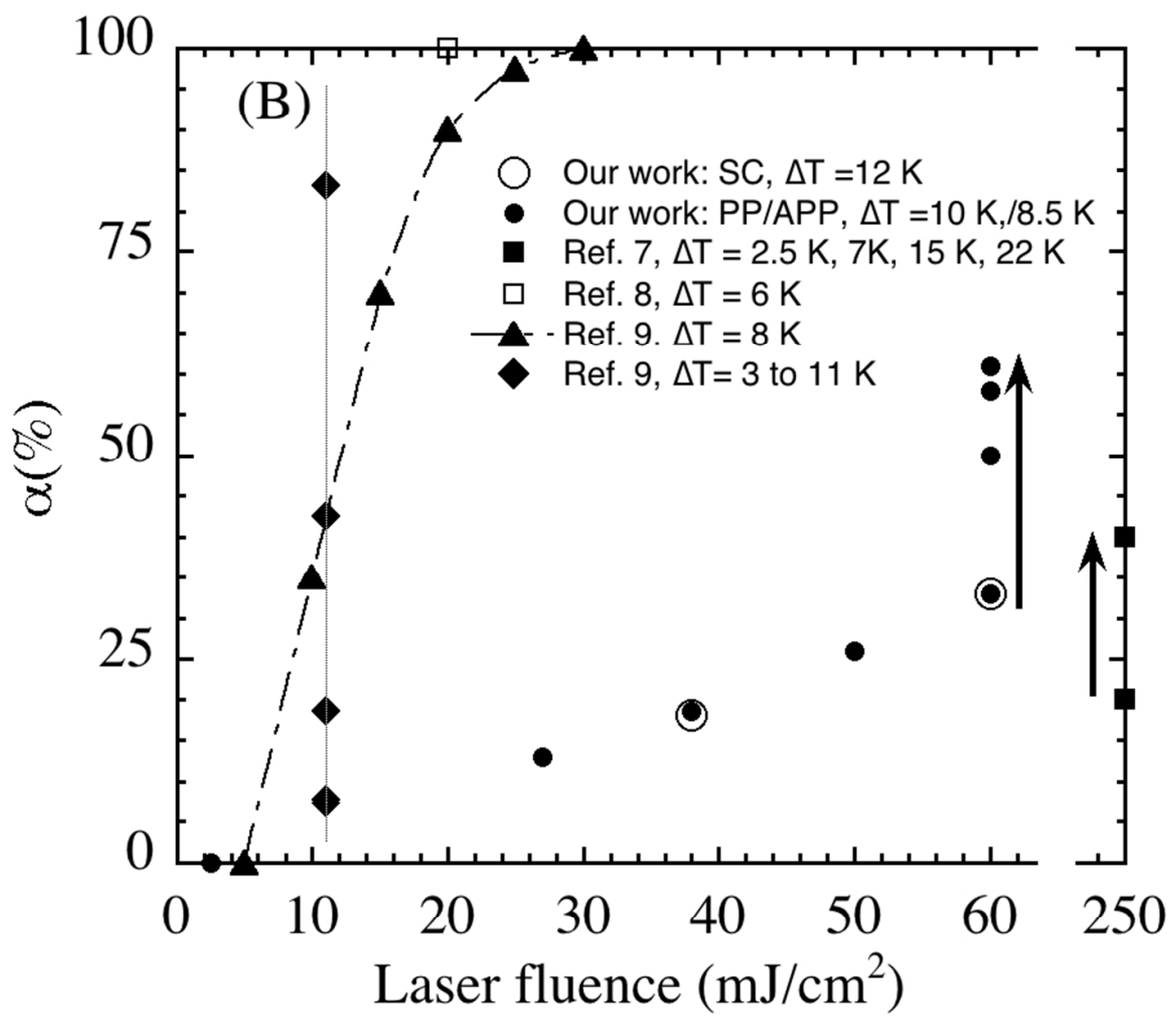

$80 \times 70 \mathrm{~mm}(288 \times 288$ DPI $)$ 


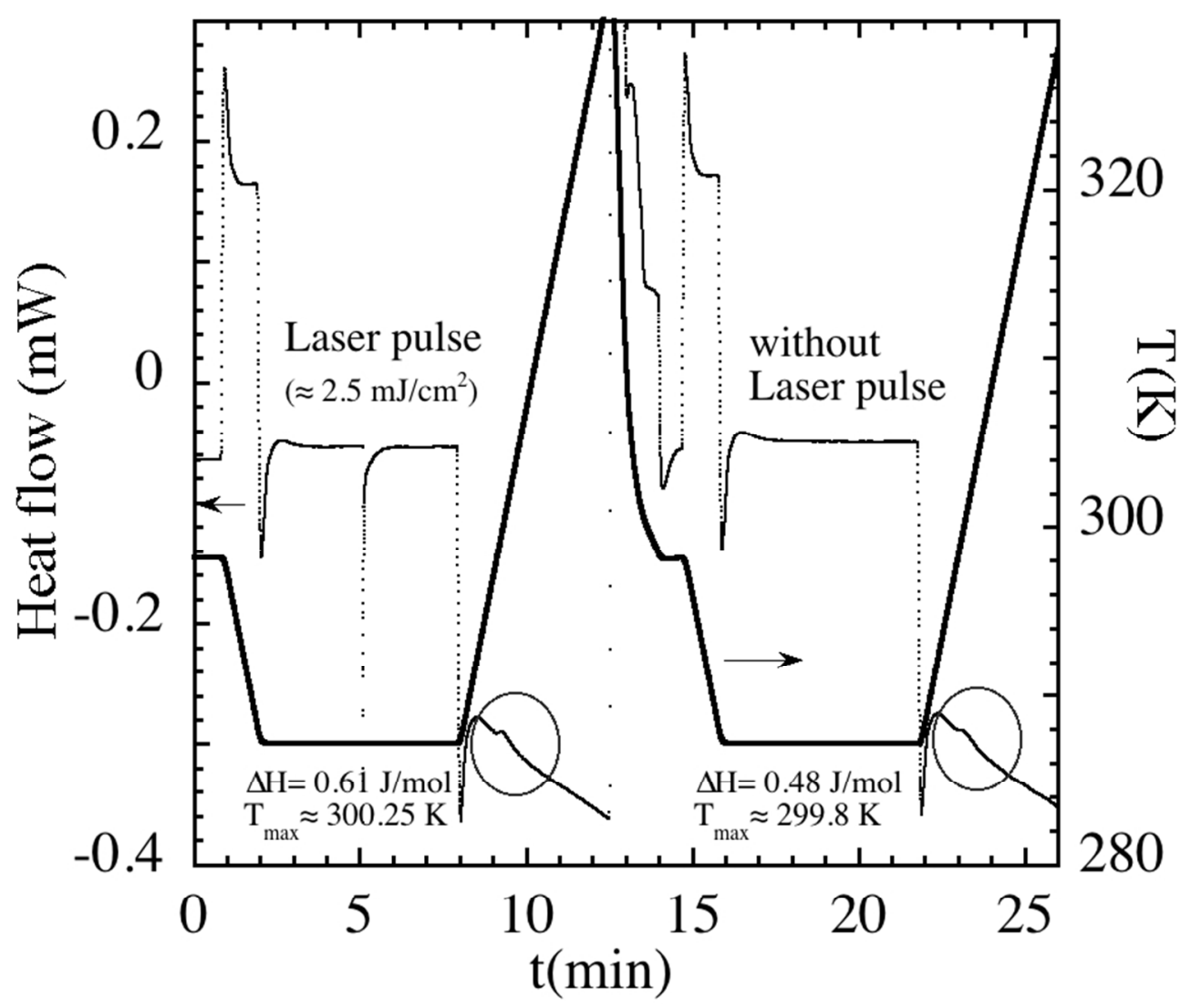

$80 \times 70 \mathrm{~mm}(288 \times 288 \mathrm{DPI})$ 


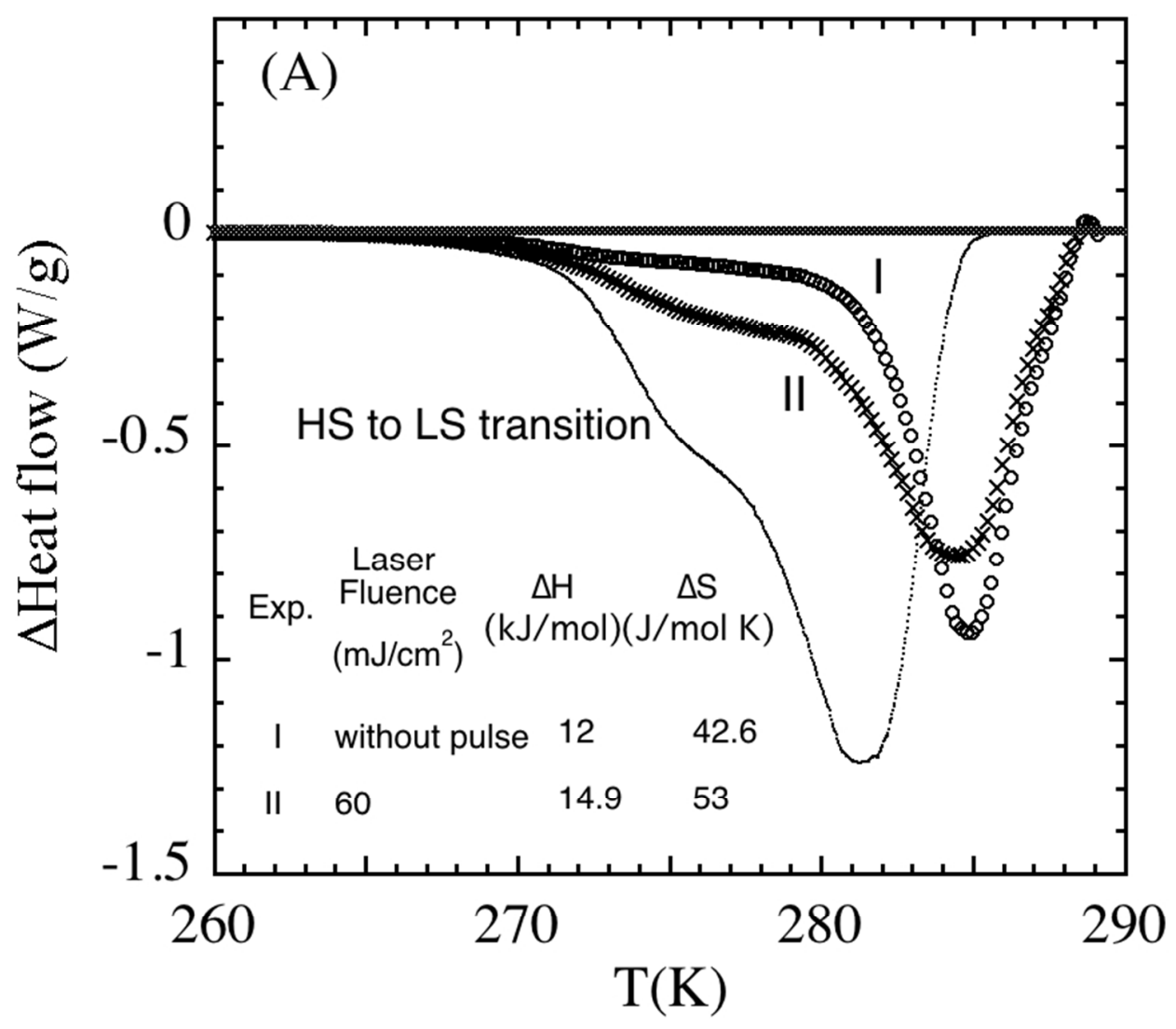

$80 \times 70 m m(288 \times 288$ DPI $)$ 


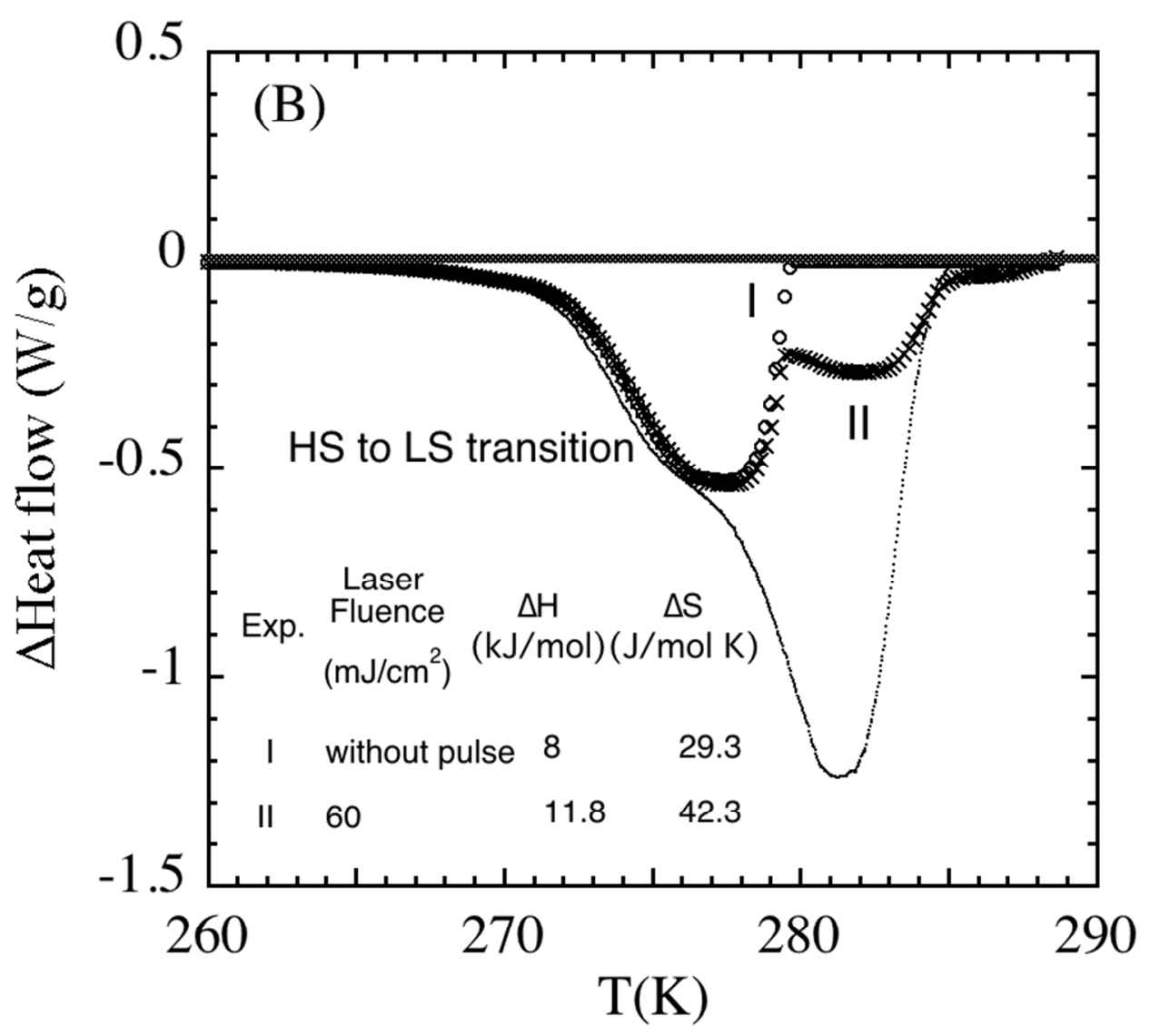

$80 \times 70 \mathrm{~mm}(288 \times 288$ DPI $)$ 


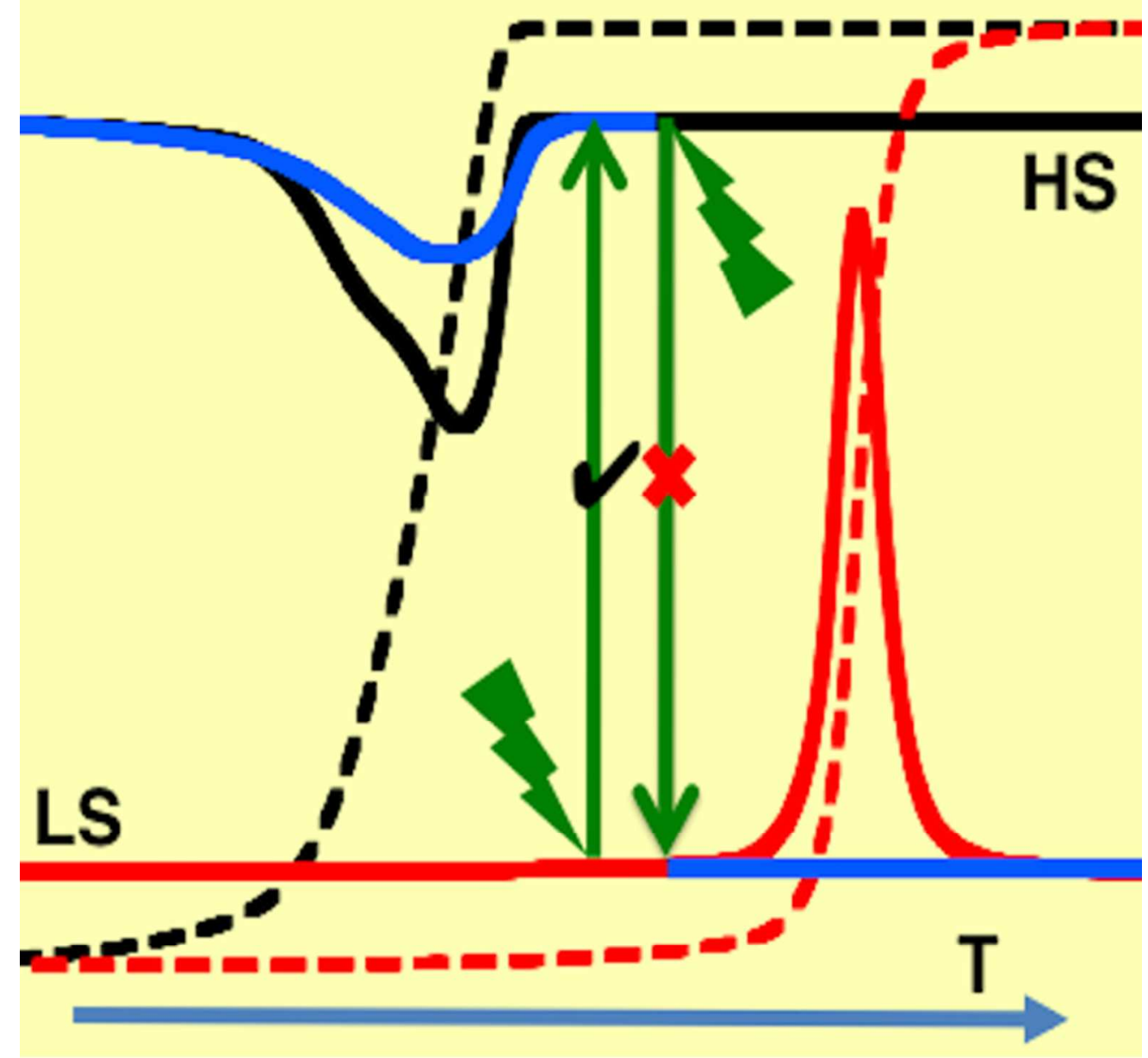

$50 \times 50 \mathrm{~mm}(300 \times 300$ DPI $)$ 